\title{
LA VERDAD EN PSICOANÁLISIS (RELACIONAL)
}

\author{
Carlos Rodríguez Sutil ${ }^{1}$ \\ $I P R$, Madrid.
}

Ciertamente, muchas demandas de tratamiento proceden de un no reconocimiento de la propia e íntima verdad. ¿Qué es la verdad? De forma predominante en nuestra cultura se concibe la verdad como correspondencia, como la adecuación entre el intelecto y la cosa. Pero existen otras versiones legítimas de la verdad. Manejamos siete tipos de verdad, a partir de Ferrater Mora y de otras fuentes, que resumimos en tres: 1) la verdad como coherencia, 2) la verdad como descubrimiento, y 3 ) la verdad como autenticidad.

La "realidad" a la que se refiere el creador del psicoanálisis no es la realidad externa, sino la realidad efectiva y propia lo que aproxima al psicoanálisis clásico, con la interpretación, a la verdad como coherencia y abre la puerta a la versión hermenéutica del psicoanálisis (Ricoeur, Habermas) y la identidad narrativa, donde el yo busca su coherencia interna. Sin embargo, el crecimiento terapéutico se alcanza mediante la co- construcción negociada de un espacio transicional, en interacción con los otros significativos. La realidad es un estado mental compartido, que se realiza en el seno del diálogo. La verdad debe ser entendida como forma de vida e integridad o autenticidad, pero no es cualitativamente diferente del descubrimiento o desvelamiento.

Palabras clave: verdad en psicoanálisis, coherencia, descubrimiento, autenticidad, hermenéutica.

Certainly, many demands for treatment come from a non-recognition of one's own intimate truth. What is the truth? Predominantly in our culture, truth is conceived as correspondence, as the correspondence between the intellect and the thing. But there are other legitimate versions of the truth. We take into account seven different types of truth, from Ferrater Mora and other sources, which we summarize in three: 1) truth as coherence, 2) truth as discovery, and 3) truth as authenticity.

The "reality" to which the creator of psychoanalysis refers is not the external reality, but the personal reality that approaches classical psychoanalysis, with interpretation, truth as coherence and opens the door to the hermeneutic version of the psychoanalysis (Ricoeur, Habermas) and narrative identity, where the self seeks its internal coherence. However, therapeutic growth is achieved through the negotiated co-construction of a transitional space, in interaction with significant others. Reality is a shared mental state, which is carried out within the dialogue. Truth must be understood as a form of life and integrity, or authenticity, but it is not qualitatively different from discovery or disclosure.

Key Words: truth in psychoanalysis, coherence, discovery, authenticity, hermeneutics.

\section{English Title: TRUTH IN RELATIONAL PSYCHOANALISYS}

\section{Cita bibliográfica / Reference citation:}

Rodríguez Sutil, C. (2019). La verdad en psicoanálisis (relacional). Clínica e Investigación Relacional, 13 (1): 185-222. [ISSN 1988-2939] [Recuperado de www.ceir.info ]

DOI: $10.21110 / 19882939.2019 .130113$

\footnotetext{
${ }^{1}$ Doctor en Psicología, Psicoanalista y Psicoterapeuta. Presidente del Instituto de Psicoterapia Relacional, Madrid, España, Miembro de IARPP. Miembro del colectivo GRITA. Premio de Ensayo "Dámaso Alonso". Entre sus publicaciones: El cuerpo y la mente. Una antropología Wittgensteiniana (Madrid: Biblioteca Nueva, 1998); Un Introducción a la obra de R.D. Fairbairn., 2010; Psicopatología Psicoanalítica Relacional, 2014 (Ambas en la colección Pensamiento Relacional, Madrid: Ágora Relacional). Dirección de contacto: crsutil56@gmail.com
} 
Verdad es la especie de error sin la cual una determinada especie de seres vivientes no podría vivir. El valor de la vida decide en última instancia.

(Nietzsche, La Voluntad de Poder, n. 493)

Se miente más de la cuenta

por falta de fantasía;

también la verdad se inventa.

(Antonio Machado, Juan de Mairena Póstumo)

\section{Introducción:}

Difícil empresa la que encaramos pues si queremos establecer cuál es el lugar que la verdad ocupa dentro del psicoanálisis, nadie nos libra, como poco, de intentar definir lo que la verdad es, dejando lo que es el psicoanálisis para, quizá, mejor momento. Pero ocurre que no existe una definición o concepto único y univoco de la verdad, sino un abanico de formas de entenderla. Fuera de la consabida "adecuación" entre el entendimiento y la cosa, engañosa imagen, como veremos, versión canónica aceptada durante siglos.

Un debate de elevada trascendencia teórica y práctica se produce a propósito de una expresión que utiliza Freud al final de la lección 31, en la Nuevas Lecciones Introductorias (1933 a, p. 2726): "Wo Es war soll Ich werden". Ballesteros tradujo al castellano de forma neutra "Donde era el ello, ha de ser yo" (p. 3146), pero que en francés se tradujo inicialmente por "Le Moi doit déloger le Ça". El verbo "déloger" quiere decir, literalmente "desplazar, desalojar". Al igual que la versión inglesa "Where it was, shall I be", daba pie a suponer que el proceso psicoanalítico es la búsqueda de una mayor adaptación a la realidad consciente. Lacan (1957) denunció que no se trata de adaptar al paciente, sino de mostrarle que se halla demasiado bien adaptado. Las propuestas de traducción alternativa serán del estilo "donde estaba el ello, el yo debe advenir". Según la primera tópica, el objeto del psicoanálisis era volver consciente lo inconsciente pero no en el sentido de una predominancia de la conciencia sino de un descubrimiento de la verdad. En esto coinciden Lacan (1966) y Bion (1962), entre otros: el psicoanálisis no es tanto una búsqueda de la curación como una persecución de la verdad.

En la sugerencia lacaniana de la excesiva adaptación del paciente se articula una de las mayores escisiones del psicoanálisis contemporáneo, que sería la que divide la aceptación matizada de la primera teoría traumática, que el joven Freud desestimó en beneficio de una atención en la dinámica interna del deseo incestuoso - y que fue la piedra de toque de su ruptura final con Ferenczi - y el psicoanálisis que busca el origen de casi todo en el ambiente, en la dinámica interpersonal familiar, tanto la patología como, más en general la formación 
del psiquismo, y que se asume en el movimiento relacional. La denuncia de la adaptación pone el peso en la dinámica interna del sujeto y acaso no hace justicia al sufrimiento traumático y la adaptación por a supervivencia, marcada por un entorno a menudo hostil. Veamos cómo Balint (1979), discípulo sobresaliente de Ferenczi, describe la formación del trauma evolutivo:

- Un niño depende de un adulto de confianza

- Ese adulto demuestra ser indigno de confianza, mediante la sobreestimulación, la negligencia o el rechazo del niño

- El niño trata de obtener alguna comprensión, reconocimiento y consuelo del mismo adulto.

- El adulto a menudo niega la perturbación, culpa al niño del trastorno y le niega la confianza

El niño percibe que sus sentimientos reactivos dolorosos no son bienvenidos o resultan lesivos para el cuidador y deben ser por tanto secuestrados defensivamente para poder conservar así un vínculo que le es necesario. Si el analista retoma esta temática y sigue refiriéndola de forma exclusiva a la dinámica deseante y pulsional del paciente, privada, sin que esa estrategia interpretativa vaya acompañada de alguna manera por el reconocimiento del daño sufrido por la persona, existe el riesgo de producir una retraumatización, aunque el paciente siga en terapia, y quizá por eso.

Afirmaba Szpilka (1973, pp. 30-38) que no hay originalmente individuos sanos que de pronto enferman, sino que es la misma escisión primordial, que nos funda como sujetos, la que nos sume en el desconocimiento de nosotros mismos. La curación que el psicoanálisis nos propone estriba esencialmente en el descubrimiento de nosotros mismos, de nuestros deseos y estructuras escindidos. La idea parece acercarse al evangélico mensaje de que la verdad nos hará libres, lo cual no quiere decir más felices. Szpilka se inspira en Althusser al teorizar que la "conciencia ideológica" es la que desconoce los mecanismos responsables de su producción, mientras que la conciencia científica implica el trabajo de descubrimiento de los mecanismos inconscientes. La psicopatología psicoanalítica, por tanto, es la que se ocupa de describir los mecanismos y configuraciones de esta conciencia ideológica, fuera de la cual de nada tenemos que curarnos. Vamos a defender aquí que, ciertamente, muchas demandas de tratamiento proceden de un no reconocimiento de la propia e íntima verdad. Sin embargo, la mayoría de nuestros pacientes padecen también importantes carencias en su historia vital, y para aliviar su dolor se requiere que reciban un adecuado reconocimiento por parte del otro.

Por lo demás, ¿si encontramos la verdad cómo la reconoceremos? Y esta no es una pregunta simple o baladí. En nuestra habla cotidiana se insertan multitud de supuestos - toda una nube 
de filosofía se condensa en una gotita de gramática (Wittgenstein, 1945-1949, II, p.222) -, a tal extremo que un observador avispado puede ponernos en un apuro con el mero expediente de pedirnos una definición precisa. En este caso ¿Qué es la verdad? Desde este momento descubrimos dos formas de verdad: la verdad del conflicto y la verdad del déficit, la primera más relacionada con la dinámica edípica de pulsiones, deseos y conflictos, situada en el inconsciente enunciativo, con el predominio de la represión y los mecanismos de defensa secundarios, de la que se ha ocupado la corriente mayoritaria del psicoanálisis a lo largo de su historia. La segunda, la verdad del déficit, encontrará su contrapunto esencial en algún tipo de elemento externo al discurso individual, en relación con el inconsciente procedimental -es decir, aquel que aún siendo aprendido nunca ha pasado por la conciencia - y que se caracteriza por la utilización de mecanismos de defensa más primitivos, como la renegación. Joan Coderch $(2007,2011)$ sugiere que la percepción de la existencia del déficit, por parte de los grandes analistas, ha sido el motor de la evolución hacia el modelo relacional.

\section{Las formas de la verdad:}

La verdad como correspondencia, que desde la Escolástica se acuñó bajo el término de adaequatio, sigue prevaleciendo en el pensamiento occidental: veritas est adaequatio intellectus ad rem, la verdad es la adecuación entre el intelecto y la cosa. En el siglo pasado con su versión del positivismo -vienés y británico- y con el atomismo lógico, la verdad de una proposición equivale a su correspondencia con la realidad. Pero existen otras versiones legítimas de la verdad ${ }^{1}$.

Resumiendo, las formas de verdad son, en principio y sin pretensiones de exhaustividad:

1) La verdad como correspondencia o adecuación, como decimos. La aplicación más simple $y$, tal vez, engañosa, de la misma, que ha dominado el pensamiento empirista es la definición ostensiva: esto es $\mathrm{x}$.

2) La verdad como cumplimiento, por ejemplo, de una promesa; esencial en la cultura hebrea.

3) La verdad como descubrimiento (aletheia): que data de la antigüedad griega y fue puesta de actualidad con la obra de Heidegger: es aquello que surge y viene a nuestro encuentro².

4) La verdad como coherencia, propia, según Ferrater, del idealismo extremo. Todo juicio particular queda absorbido en un juicio total. Sin embargo, en la filosofía de la ciencia del siglo pasado - autores como Lakatos, Kuhn o Popper -, la coherencia de los sistemas de representación ha venido a completar la mera correspondencia, 
en cuanto se evidenció que ningún juicio ostensivo - "esto es un gato" - es decir siquiera imaginable fuera de categorías más amplias (animales, mamíferos, perros, gatos, caballos, etc.).

5) La verdad como coincidencia del hombre consigo mismo (Ortega). El hombre necesita justificar por qué en algunas ocasiones se dedica a averiguar el ser de las cosas: porque el conocimiento es el acto que le salva del naufragio de la existencia. El saber se convierte de este modo en saber a qué atenerse. A simple vista parece una idea afín al concepto de integridad que propone Heidegger.

6) La verdad como creación ejecutiva. Sería la verdad ejecutiva o performativa que proponen los filósofos británicos del lenguaje corriente, como Austin o Strawson. El propio acto de enunciar la proposición la convierte en verdadera: "yo os declaro marido y mujer", "yo te nombro mi heredero", y las profecías autocumplidas: "hijo mío, tú nunca llegarás a nada".

7) La verdad como utilidad. Procedente de los pragmatistas norteamericanos (Peirce, James). Una proposición es verdadera en la medida que reporta una utilidad, no obligatoriamente en un sentido material estricto y vulgar, sino como un beneficio vital para la persona y el grupo.

Todas estas versiones de la verdad tienen su correspondencia en la práctica psicoanalítica y, probablemente, en toda forma de psicoterapia que merezca tal nombre. Pero, por otra parte, algunos de sus rasgos diferenciales se difuminan cuando intentamos captar su dinámica en la práctica. Para nuestros objetivos aquí, las reagruparemos en tres apartados o rótulos globales en los que se engarzan:

1) La verdad como coherencia o sistema, que incluye la correspondencia y, al menos en parte, la utilidad.

2) La verdad como descubrimiento, relacionada con las otras pero sin llegar a integrarlas.

3) La verdad como autenticidad, que incluye el cumplimiento, la utilidad y la creación ejecutiva.

Una meditación somera nos lleva a descubrir que los tres grupos de verdad, a su vez, no tienen por qué estar radicalmente separados, pues se implican, aunque no se confundan. La verdad como sistema incluye la correspondencia, en cuanto ya no la aceptamos como una operación aislada, y la utilidad, pues será útil aquella verdad que sirva para alcanzar un sistema más adecuado por sus consecuencias prácticas. El tercer epígrafe es, desde luego, el que muestra una multiplicidad en apariencia más abigarrada de conceptos, retomando la utilidad del 
pragmatismo, pero que podrían ser integrados en una unidad superior. Añadiremos argumentos después, pero, de momento, pensemos que una verdad es útil porque puede ser utilizada para alcanzar ciertos objetivos, que es lo mismo que decir que no es tal verdad si una vez enunciada no cambia nada. El enunciado es auténtico, en estos casos, porque se cumple - alguien lo cumple - o puede ser comprobado, mediata o inmediatamente, como ocurre con una promesa. En una promesa yo comprometo mi acción, en una aseveración me comprometo en relación con un hecho concreto. Ahora bien, en la medida en que se cumple, "crea" la realidad a la que se refiere, es ejecutiva.

\section{Verdad como coherencia del sistema}

Para el Wittgenstein maduro, partidario del principio de coherencia, toda conceptualización de la realidad se logra desde un "sistema": un juego de lenguaje, por muy simple que sea. Un "juego de lenguaje" es el todo compuesto por el lenguaje y las acciones con las que está entretejido (Wittgenstein, 1945-49, I, \ 7). Por el camino del uso y de los juegos de lenguaje llegamos a las "formas de vida" (Lebensformen), donde se insertan nuestras palabras y acciones. Para Wittgenstein - que no suele hablar de "verdad" (Wahrheit) sino de "certeza" (Gewissheit) - la certeza no proviene del mundo fenoménico sino del sistema del lenguaje, una actividad gobernada por reglas, reglas públicas, y decir "públicas" es un pleonasmo. Verdadero y falso es lo que los hombres dicen, pero los hombres están de acuerdo en el lenguaje que utilizan, concordancia que, defiende, no es de opiniones sino de forma de vida (1945-49, I, \241). El acuerdo en formas de vida sería previo, desde un punto de vista lógico, al acuerdo en la opinión sobre lo que es y lo que no es el caso, lo que puede significar el consenso interpersonal sobre la verdad o falsedad de una amplia proporción de proposiciones empíricas: "El sistema no es el punto de partida, sino el elemento vital de los argumentos" (Wittgenstein, 1949, p. 105). El empirismo lógico vienés y británico que tomó su primer texto - el Tractatus (1918) - como ideario, se mantuvo en la concepción de la verdad como correspondencia: la proposición se corresponde con el hecho en la medida que comparten la forma lógica.

Adolf Grünbaum (1984), autor encuadrado en el empirismo (lógico), realizó una de las pocas críticas bien documentadas que se han hecho desde esa perspectiva hacia el psicoanálisis freudiano. Bautiza el argumento epistemológico central del psicoanálisis con el término de "Tally argument", que en español podríamos denominar, precisamente, "argumento de correspondencia"3. Freud, en la lección XXVIII de sus Lecciones Introductorias (1916-1917), propone que la interpretación constituye el método de acción psicoanalítica por antonomasia, 
efectivo cuando es correcta y es enunciada en el momento oportuno, favorable para que el sujeto la acepte e integre, algo que no puede ser logrado por la mera sugestión:

No es, desde luego, difícil hacerles aceptar una determinada teoría y compartir un error del médico. Comportándose el paciente como cualquier otro sujeto, por ejemplo, un alumno [frente a su profesor], pero en este caso se habrá influido únicamente sobre su inteligencia y no sobre su enfermedad. La solución de sus conflictos y la supresión de sus resistencias no se consiguen más que cuando les hemos proporcionado representaciones anticipatorias (Erwartungsvorstellungen) que en ellos coinciden con la realidad (Wirklichkeit). Aquello que en las hipótesis del médico no corresponde a esta realidad, queda espontáneamente eliminado en el curso del análisis y debe ser retirado y reemplazado por hipótesis más exactas. (pp. 2404$5)^{4}$

Para Grünbaum la interpretación acertada sería aquella que se corresponde con lo real externo y, en consecuencia, no considera que el psicoanálisis sea científico, pues nunca será susceptible de una corroboración externa con garantías. Por poner un ejemplo, si se interpreta que la reacción de tristeza que experimenta un paciente en un momento determinado es una estrategia defensiva para ocultar sus deseos envidiosos en relación con su hermano, la aceptación - o no aceptación - del paciente carecerá de cualquier valor probatorio pues no se podrá seguir el procedimiento estándar de contrastación de hipótesis empíricas, y todo puede ser resultado de la mera sugestión o de la reacción contra ella. Sin embargo, la "realidad" a la que se refiere el creador del psicoanálisis no es la realidad objetiva y externa al sujeto, para lo cual Freud habría utilizado seguramente el vocablo Realität, sino la realidad efectiva y propia del sujeto (Wirklichkeit). Esto, por una parte, aproxima la interpretación a la verdad como coherencia o sistema y, por otra, abre la puerta a la versión hermenéutica del psicoanálisis, propuesta por autores como Paul Ricoeur (1965), o Jurgen Habermas (1968, cap. XI), que lo conciben como una ciencia de la interpretación, más que como una ciencia natural; alejada, por consiguiente, de los procedimientos habituales de comprobación empírica.

Freud se enfrentó de manera resuelta con este asunto en en uno de sus trabajos tardíos, Construcciones en Psicoanálisis (1937 b) donde plantea que no vale lo mismo cualquier interpretación. Hay interpretaciones que producen los efectos esperados y otras no, aciertan con la realidad psíquica del paciente o fallan. Tampoco basta con que el paciente confirme o rechace la interpretación; hay que esperar y ver si se producen cambios. La interpretación correcta es, pues, la interpretación fecunda, la que fortalece la "identidad narrativa", en el sentido de Ricoeur (1998). Pero, si bien se mira, cuando atendemos al efecto que la interpretación produce, nos situamos en la órbita de la verdad útil de los pragmatistas. Esta identidad narrativa, en la que el yo busca su coherencia interna, se halla en la órbita de la 
verdad como sistema, pero siempre quedará un resquicio para lo inesperado, el descubrimiento sorprendente. $Y$, como es evidente, la coherencia narrativa no puede ajustarse sólo en una reconstrucción histórica, sino que debe surgir de la vivencia del aquí y ahora de la relación, de la dupla terapéutica.

Dice Freud:

El camino que empieza en la construcción del analista debería acabar en los recuerdos del paciente, pero no siempre llega tan lejos. Con mucha frecuencia no logramos que el paciente recuerde lo que ha sido reprimido. En lugar de ello, si el análisis es llevado correctamente, producimos en él una firme convicción de la verdad de la construcción que logra el mismo resultado terapéutico que un recuerdo vuelto a evocar. El problema de en qué circunstancias ocurre esto y de cómo es posible que lo que parece ser un sustituto incompleto produzca un resultado completo, todo esto constituye el objeto de una investigación posterior. (1937 b, p. 3371)

Podría pensarse en el peligro de que el juego de las interpretaciones nunca termine y todas sean defendibles. Freud es tajante en contra de esto, la interpretación o construcción correcta es la que provoca la reeducación emocional del paciente, que elimina los síntomas patológicos, y suscita asociaciones, recuerdos o impresiones que relanzan el proceso. Mitchell (1993) argumenta con sagacidad que esta sensibilidad a la interpretación "correcta" está lejos de ser "ateórica":

Abandonar la creencia en una Verdad analítica, única y objetiva (o en muchas verdades analíticas que se aproximan a una realidad, objetiva y singular) no conduce a un relativismo sin valores. Existe una cantidad infinita de formas de pintar un jarrón con flores, eso no quiere decir que todas ellas sean igualmente conmovedoras, que puedan hacerse acreedoras por igual de capturar y transformar la experiencia. (p. 65)

Bromberg (2011, p. 97) discute con la filósofa Marcia Cavell (2000) sobre su concepción de la realidad. Cavell defiende que, aunque existen muchos puntos de vista, la realidad es una y la misma para todos nosotros, mientras que él opina que esto es problemático para el clínico, alguien que siempre está trabajando en un campo complejo donde esa distinción impediría el crecimiento personal más que facilitarlo. Cuando se afirma, y son multitud los filósofos que lo han hecho a parte de Cavell, que la realidad es una a pesar de las apariencias, eso da por supuesto que alguien tiene el privilegio de alzarse sobre las visiones parciales de los demás para ofrecer su "inmaculada percepción" de una realidad a parte de sus manifestaciones fenoménicas. No podemos atestiguar que la realidad es una ni que es múltiple, sino que somos nosotros los que una vez la percibimos de una manera y otras veces de otra. Se trataría de esas proposiciones que, como descubrió el primer Wittgenstein (1918), requieren que tomemos al 
mundo en su totalidad y nosotros nos coloquemos fuera, algo imposible desde el punto de vista lógico y material y que él situaba en el ámbito de lo místico.

El crecimiento terapéutico - sugiere Bromberg - se alcanza mediante la coconstrucción negociada de un espacio transicional en el que, como ya vio Winnicott (1951), la cuestión de la verdad o de la falsedad pierde su significado. Esta construcción de la realidad se hace en interacción con los otros significativos. La realidad es un estado mental compartido, que se realiza en el seno del diálogo, ya sea el diálogo con el otro o con el otro interior.

Junto a Mitchell, los relacionalistas invocan la situación de dos seres humanos que crean juntos, una verdad - tanto objetiva como subjetiva - no aislada dentro de la mente de uno u otro, sino algo que buscan y encuentran ambos, una realidad compartida, transicional, si se quiere. La verdad no es tanto una realidad objetiva sino el producto cocreado por parte de dos o más seres humanos. Podríamos decir que la verdad es una cosa que hemos perdido ambos, que necesitamos y que recuperaremos si estamos dispuestos a llegar al fin del mundo caminando tomados de la mano (Bromberg, 2009, p. 349).

La realidad no surge a partir de la nada, pues, si queremos sobrevivir, nuestras representaciones no pueden ser arbitrarias. No somos creadores ex nihilo sino, como mucho, demiurgos. Con frecuencia descubrimos que unas representaciones son verdaderas, por ejemplo, la leña arde, y otras son falsas, por ejemplo, una paloma no puede volar en el vacío. Si descubrimos que la representación es falsa buscamos rápidamente una representación alternativa que encaje mejor con la "realidad", es decir, que sea coherente con el sistema, a veces incluso promoviendo una reforma de todo él, pues ninguna representación se da aislada. La realidad es lo subjetivo social (Berger y Luckmann, 1986), lo que significa que tanto verdad como falsedad son formas de representarse el mundo, que no vienen originariamente del interior de la mente individual, sino de la comunicación social, pues la existencia del mundo es a priori. En realidad, no habría que demostrar la existencia del mundo "exterior", sino más bien la triste tendencia que tenemos sepultar ese mundo bajo teorías del conocimiento, para luego intentar probarlo (Heidegger, 1927, \43, p. 227).

El ser humano (el Dasein) es un ser con los otros (Mitsein) desde el principio, no es subjetividad sino cura (sorge, "care" en inglés), cuidarse de los otros desde el principio y, por tanto, el sujeto nunca está totalmente aislado en un narcisismo primitivo y en un principio del placer. Como bien nos descubrió Ronald Fairbairn (1958, p. 85), el principio del placer es una generalización errónea a partir de un fenómeno defensivo. El principio del placer sólo puede operar en un sistema cerrado y el mantenimiento de la realidad interna como sistema cerrado es un fenómeno esencialmente psicopatológico. 
Durante los Seminarios organizados después de la segunda guerra por Medard Boss en Zollikon, una localidad suiza, Heidegger (1987) desmenuzó, ante una audiencia de psiquiatras, los elementos positivistas del psicoanálisis freudiano. Utiliza argumentos muy cercanos a la crítica humanista y a la que, muy próxima a ésta, se viene desarrollando en el psicoanálisis relacional, sobre todo en la versión intersubjetiva de Stolorow y su grupo (Orange, 2010: Orange, Atwood y Stolorow, 1997; Stolorow, Orange y Atwood, 2001). El psicoanálisis es entonces descalificado no por caer en el ámbito de la pseudociencia, sino por ser excesivamente cientifista. El filósofo alemán denuncia que la metapsicología transfiere la teoría kantiana de la objetividad al estudio del hombre - lo convierte en objeto - $y$, una vez hecho eso, somete dicho estudio al paradigma de las ciencias naturales. Por el primer movimiento Freud provoca una objetivación inaceptable de la historicidad humana, convirtiendo al hombre en algo meramente a la vista o presente (Vorhanden) - una realidad efectiva, un objeto -. Por el segundo movimiento, lo naturaliza como si estuviera inscrito en un proceso causal, no ofrece la historia del ser humano concreto sino una cadena de causas naturales. Se le concede, no obstante, el mérito indudable de haber puesto al descubierto que los seres humanos enferman debido a relaciones traumáticas con seres humanos, y, como corolario, su demostración de que los trastornos pueden ser curados a través de la relación con otros seres humanos - los terapeutas -. Pero esto debería, en realidad, estimarse como un modo específico de estar con los otros, sin el concurso de conceptos - como el de "transferencia" - que evidencian una teoría sobre mentes separadas y estancas. La analítica existencial (Daseinanálisis), al contrario, ha de ser una ciencia descriptiva, no constructiva ni hipotética. Puesto que la vida del individuo es esencialmente un fenómeno histórico, y el tiempo existencial es circular, la comprensión deberá describir un movimiento también circular.

En resumen, el psicoanálisis entendido como una técnica da por supuesto que una mente aislada, el analista, le está haciendo algo a otra mente aislada, el paciente, o, en el peor de los caos, a la inversa. Si decidimos objetivizar al ser humano, añade Heidegger (1987, p. 215), desde ese momento lo relevante no es el ser humano sino la psicoterapia, que se convierte de inmediato en algo puramente técnico, luego su resultado no puede ser un ser humano más sano, sino, en el caso más favorable, un objeto más pulido. De esa manera se explicaría, podemos añadir, que las recomendaciones técnicas - que inicialmente solo eran consejos orientativos - se conviertan en reglas fijas de obligado cumplimiento, que perviven en nuestro "superyó psicoanalítico colectivo." (Orange, Atwood y Stolorow, 1997, p. 15).

Cuenta Philip Bromberg (2011) que, durante una entrevista con su primer supervisor analítico, comentó que había descubierto que lo que había dicho una paciente no era verdadero. El supervisor le preguntó entonces: "¿Qué quiere decir con verdadero?". Bromberg, un tanto 
irritado, le respondió que lo que la paciente decía no era verdad, a lo que el supervisor objetó: "Más bien lo que parece es que no era exacto". El analista veterano estaba haciendo una distinción entre lo que es verdadero y lo que es exacto. Freud restó importancia a lo Real (Realität) "externo", cuando abandonó la inicial teoría de la seducción infantil para explicar los síntomas histéricos y la sustituyó por los deseos inconscientes y reprimidos de dicha seducción. Lo único que parece importar es la dinámica interna de la persona. El supervisor de Bromberg seguía ese criterio. Lacan (1953-54), en su Seminario I, lo expresa de manera taxativa. Poco importa, según él, que el discurso del sujeto concuerde o no con la realidad, lo único que importa es que se diga a sí mismo en su verdad. La verdad es distinta de la realidad, se opone a la realidad. En cualquier caso, parece una tendencia general en el psicoanálisis poner el foco en la realidad subjetiva o interna y no atender a la realidad histórica (Cf. Ricoeur, 1977). Precisamente esa es la razón de que desde el psicoanálisis relacional se tema que la posición clásica acarrea el depositar toda la problemática en el individuo y a desatender las causas externas $y$, en último término, a no percibir el traumatismo y las causas reales de sufrimiento. Pongamos un ejemplo.

Un paciente en la mitad de la veintena dice que sus padres siempre le han respetado mucho y él les está muy agradecido por eso. Comenta que siendo todavía adolescente llegó alguna vez a casa bebido, y que entonces se iba derecho a su habitación, sin que sus padres le dijeran nada. Extrañado, el terapeuta le comenta que no parece la reacción más adecuada de unos padres que quieren a su hijo y se interesan por él. Inicialmente no acepta la observación, pero lo que subyace es una temática relacionada con el rencor hacia sus padres, que más adelante pudo ser trabajada. La observación del terapeuta no es propiamente una interpretación sino una confrontación, aunque preferiría decir "un juicio de realidad", en el que él adopta la posición de cuidador de la que el paciente debió carecer en su historia. Se podría decir que en la realidad o dinámica interna del paciente (Wirklichkeit) se halla implícita esa denuncia hacia los padres. Pero a lo que el terapeuta ha recurrido, legítimamente, es a su experiencia personal de la realidad externa. Esta anécdota nos permite deducir la realidad externa y en cierta medida, "objetiva", de esa historia personal de abandono, que en principio no coincide con la realidad subjetiva del paciente.

La verdad de una interpretación o de cualquier otra intervención clínica procede, en parte, de la coherencia narrativa, es decir, de la adecuación a la historia vital del paciente, lo que da lugar a diferentes opciones de coherencia narrativa. Pero, como se ve en el ejemplo, la valoración de la coherencia no se queda exclusivamente en el nivel interno del discurso, sino que también se constata con la realidad externa, accesible dentro y fuera del reducido espacio de la consulta. El instrumento terapéutico de la confrontación, al menos como nosotros lo entendemos, va en esa misma dirección. La mera devolución por parte del analista de un 
resumen de aquello que el paciente le ha comunicado - incluso la no devolución, el gesto que acompaña al diálogo, el murmullo o la más artificial de todas las respuestas, la paralización supone una selección valorativa de aquellos contenidos más significativos, de acuerdo con los criterios del terapeuta y con su visión de la realidad que engloba a ambos.

Marcia Cavell (1993, págs. 126-134) ve la necesidad de un psicoanálisis hermenéutico, por tratarse de una ciencia más blanda que la física, pero mantiene que las interpretaciones descubren vínculos de naturaleza causal y propone las razones son causas. Con esto tal vez supera el riesgo de apartarse de Freud más de lo deseado, pero a costa de no resolver problema epistémico alguno. Una versión hermenéutica simple del psicoanálisis también entraña riesgos, como es la posibilidad de que surjan diversas perspectivas o versiones difícilmente compatibles de la misma realidad. Nos asomamos al abismo del "todo vale", de moda en tiempos "postmodernos", del que no nos libraremos por el solo hecho de que toda interpretación sea una construcción. Si no hay ninguna base material que sirva de anclaje, una interpretación valdrá lo mismo que otra y, en definitiva, nada. Para Ricoeur (1965, pp. 455456) Freud, a pesar de toda su construcción hermenéutica, no se decidía a abandonar la energética, porque el método psicoanalítico es impracticable si no se acepta el modelo naturalista impuesto por el principio económico.

Una transcripción puramente lingüística elude la dificultad fundamental: el naturalismo del psicoanálisis podría estar bien fundado en el aspecto casi natural de las fuerzas subyacentes al psiquismo, las pulsiones, por tanto. Pero el punto de anclaje desde el constructivismo que asume el psicoanálisis relacional no es la teoría de la libido, sino el apego, la búsqueda del objeto como motivación básica del organismo humano y, por otra parte, la recuperación del ambientalismo de la primera teoría traumática freudiana: la seducción. Algo que Winnicott introdujo con su concepto de la "madre suficientemente buena". Ahora bien, nuestro retorno a la teoría de la seducción - siguiendo a Kohut (1984, p. 27) - no se refiere obligatoriamente a actividades sexuales manifiestas sino, más bien, a carencias empáticas por parte de los "objetos del self" paternos.

La perspectiva constructivista - advierte Orange (2010) - tiende a distanciarnos como terapeutas de las atrocidades que han vivido nuestros pacientes, y nos protege de vivirlas con ellos. Nos convierte en una versión moderada de los padres invalidantes, y nuestra actitud distanciada puede retraumatizar. No obstante, el constructivismo - y aquí parece aplicable lo que afirma Grondin (1991, p. 38) del "perspectivismo" - no debe ser entendido, siempre que la construcción se elabore en una permanente y dialéctica de colaboración, como un pensamiento de la resignación, sino como una filosofía crítica cuyo objeto es rechazar pretensiones de conocimiento indemostrables. 


\section{Verdad como descubrimiento (aletheia)}

¿Por qué acuden los pacientes en busca de ayuda? Sabemos que cuando alguien demanda ayuda ya ha intentado una solución, fallida, a su historia, ya se ha "construido" algunas explicaciones sobre lo que le pasa o lo que siente. Pero estas explicaciones no han bastado, no han reportado alivio y, sobre todo, solo han servido para estancar el proceso de elaboración (Verarbeitung) deparando una mayor angustia u otros síntomas. Levenson (1912) ha sugerido con cierta malicia y bastante sagacidad que la gente va a tratamiento porque su neurosis ha dejado de funcionar y quiere que se le arregle. Quizá lo que busca el paciente, acaso sin saberlo, es otra construcción, algo que dé sentido a su historia, queriendo descubrir quién es "realmente", por lo que un objetivo importante del tratamiento es mostrarle que la persona que teme o espera ser no refleja su "verdad" con mayor exactitud que aquella parte que se muestra al mundo. Esto se ejemplifica con la antigua frase de: "un histérico es alguien que va por la vida pretendiendo ser quien realmente es". De ahí la utilidad de las interpretaciones y/o construcciones hipotéticas del analista, que devienen correctas por el efecto de conmoción activadora que producen en el paciente. A veces se ha intentado equiparar el análisis con un proceso educativo. Sin embargo, lo que el paciente busca es la "salvación" de sus objetos internos malos, del odio y la culpa (Fairbairn,1943). El psicoterapeuta es un sucesor del exorcista. Su misión no es tanto perdonar los pecados, sino desalojar los demonios. (1943, p. 79), lo que, si no nos quedamos en la mera abreacción, nos empuja hacia la verdad como descubrimiento.

La verdad como descubrimiento es anunciada por Ortega, en el sentido que después tomará en Heidegger, pues ya se encontraría en el fermento cultural germano que ambos compartieron:

Las verdades, una vez sabidas, adquieren una costra utilitaria; no nos interesan ya como verdades sino como recetas útiles. Esa pura iluminación subitánea que caracteriza a la verdad, tiénela ésta sólo en el instante de su descubrimiento. Por eso su nombre griego, aletheia, significó originariamente lo mismo que después la palabra apocalipsis, es decir, descubrimiento, revelación, propiamente desvelación, quitar un velo o cubridor. (Ortega, 1914, p. 41)

Heidegger (1927) pretende evitar las adherencias metafísicas y teológicas que arrastra el vocablo "hombre" sustituyéndolo por el término germano Dasein, en principio intraducible, como muchos otros del filósofo alemán, por lo que se ha vertido al castellano de muchas maneras, entre otras manteniendo la propia palabra "Dasein", también "ser-en-el-mundo", "ser-ahi" - la más literal - o este "estar": 
El estar es ser-en-el-mundo, es decir: él "es" su mundo, es a partir de estar familiarizado con el mundo. Y si no es un objeto que viene a darse en el "mundo", en la suma total de lo ente, tanto menos es un sujeto carente de mundo a partir del cual, como desde Descartes se había venido intentando continuamente, hubiera que tender primero el puente hacia el "mundo". Más bien el estar, en cuanto ser-en-el-mundo, está ya siempre cabe las cosas, así como ya siempre con otros. El estar no es un Yo que tuviera que acoger en sí la referencia a otros hombres, sino que está primariamente en el ser-con otros (O. Pöggeler, 1986, p.56).

La esencia de dicho ente reside en su propia existencia, existencia inseparablemente integrada en el mundo de la relación con los otros, en su "ser relativamente a". (Heidegger, 1927, ST, \$ 9, p.54). Como decíamos, la dilucidación del "ser en el mundo" mostró que no "es" inmediatamente, ni jamás se da un mero sujeto sin mundo. Ni por tanto a la postre se da inmediatamente un yo aislado de los otros $(1927, \$ 25$, p. 132). Así, una realidad tan íntima como el estado de ánimo (Stimmung) no debe confundirse con un estado interno y cerrado, sino que es una forma peculiar de estar abierto al mundo (1927, \29), un modo de "encontrarse" (Befindlichkeit), y siempre estamos abiertos al mundo desde nuestro estado de ánimo. El conocimiento es igualmente un modo de ser del Dasein $(1927, \$ 13)$. El conocimiento se funda, por anticipado, en un ser ya en el mundo, que no es un rígido estar mirando con la boca abierta, sino activo, ocupado en el mundo, "curándose" de él. El detenerse junto al ente que se quiere conocer supone no abandonar la esfera interna, sino que conocemos en la medida en que estamos en el mundo. Incluso el olvido de algo debe concebirse como una modificación del original "ser en" y de la misma forma toda ilusión y todo error. De manera no incompatible con eso, Wittgenstein afirmará, en algunos pasajes de las Philosophical Investigations, que el conocimiento del alfabeto no es un estado del aparato mental, sino que simplemente es un estado (de una persona) (1945-49, I, \149, \572, \573).

Tras la lectura del parágrafo 7 de Ser y Tiempo (El Método Fenomenológico de la Investigación) sabemos que el término griego "fenómeno" quiere decir "lo que se muestra", lo patente, aquello que es sacado a la luz del día. Todos los indicios, signos, síntomas y símbolos tienen la estructura formal del aparecerse. Apartándonos bruscamente del lenguaje heideggeriano aunque solo sea para tomar aire en la superficie - insistiremos en que la realidad es construida, ahora bien, no a partir de la nada. Verdad es la percepción de algo: el ver descubre siempre colores, el oír descubre siempre sonidos. La verdad es percepción y descubrimiento. Nunca es falsa, aunque puede quedarse en un no-percibir, un no bastar para tener el acceso adecuado. "Tras" el fenómeno no hay ninguna otra esencia, nada oculto salvo lo que se va volviendo fenómeno, pues la apariencia es la efectiva y única realidad de las cosas. Ciertamente los fenómenos no nos son dados de forma completa e inmediata, sino que se van dando. El ser real es en sí mismo perspectivista. Puede que un fenómeno todavía no haya sido descubierto, 
o haya quedado enterrado, después de haber estado descubierto (1927, p. 46). Si no está enterrado del todo se nos muestra en la forma del "parece ser...", que puede engañarnos. De alguna manera estas afirmaciones podrían hacerse concordar con las dos formas del inconsciente del psicoanálisis contemporáneo: el inconsciente procedimental - lo no descubierto - y el inconsciente declarativo o dinámico en el sentido freudiano, esto es, lo enterrado o reprimido.

Heidegger se explicó, tal vez, con mayores concesiones de lo habitual hacia la audiencia, en una serie de conferencias impartidas entre 1930 y 1932 con el título de Sobre la Esencia de la Verdad (1943). Comienza analizando el concepto corriente de "verdad", la verdad como forma de ser del objeto: el oro "verdadero" frente al cobre dorado. Una proposición es verdadera cuando su significado concuerda con la cosa que juzga, pero se trata de un camino de ida y vuelta o de una doble concordancia. El acuerdo entre la cosa y lo que se supone que es y, en segundo lugar, la concordancia entre lo que la proposición significa y la cosa misma. Se puede entender que la verdad es la adecuación de la cosa con el conocimiento, pero también que la verdad es la adecuación entre el conocimiento y la cosa. A hora bien, ambas concepciones toman la verdad como conformidad, concordancia, adecuación. La concepción kantiana de que los objetos se adecúan a nuestro conocimiento se deriva de la fe cristiana y de la idea teológica de que las cosas, tanto por su esencia como por su existencia, son creadas y se corresponden con la idea concebida previamente por el intelecto divino, es decir, por Dios. Ese dato garantiza la verdad como adecuación del intelecto humano a la cosa creada, y ese orden, una vez desvinculado de toda referencia teológica, puede ser ofrecido de manera general como orden del mundo, $\mathrm{y}$, en consecuencia, la verdad como correspondencia queda establecida como la realidad natural. Incluso los que se esfuerzan por explicar esta correspondencia la presuponen ya como la esencia de la verdad, que ha adquirido una validez evidente. La noverdad puede ser desatendida, en tanto que criterio.

Pero ¿acaso sabemos lo que significa la concordancia entre una proposición y la cosa? ¿Cómo es posible que un enunciado, manteniendo su esencia, pueda corresponder con una cosa? Esto intentaron resolver, con la forma lógica de la proposición, los representantes del positivismo lógico como Russell y el primer Wittgenstein.

Una proposición es verdadera cuando descubre al ente en sí mismo, cuando muestra, cuando permite ver al ente en su estado de descubierto. Esta visión se aleja de la simple concordancia entre el conocer y el objeto, en el sentido de una adecuación de un ente (sujeto) a otro (objeto) (1927, \44, p. 239). La comprobación entraña el "ser descubierto" del ente mismo, el mostrarse de los entes en su identidad. Una proposición debe, por tanto, considerarse verdadera no porque coincida con un ente sino porque permite ver al ente en su estado de 
descubrimiento. La falsedad, por su parte, no es un fenómeno completamente ajeno a la verdad, que debamos apartar sin más, sino que es una forma parcial o provisional de mostrarse el fenómeno, constituye una determinación esencial de nuestro ser en el mundo. Wittgenstein, a su manera, sugiere que mentir es un juego de lenguaje que requiere ser aprendido como cualquier otro (1945-49, I, 249, 250); igualmente, sólo es posible la duda cuando ya existe la certeza $(1945-48,410 ; 1949,310)$, podemos decir que sólo es posible la mentira cuando ya existe la verdad.

La verdad se hace patente sólo en la medida en que el juicio, mediante el cual se enuncia, se refiera a la cosa de la que se afirma la verdad, en la medida en que la haga presente y permita expresarla tal como es. La cosa, por ende, debe aparecer en una apertura que nos dirija hacia ella. La aparición de la cosa y, por extensión, del hecho, se produce en un espacio de encuentro, en una apertura, como campo de relación.

Ahora bien, no somos nosotros quienes suponemos la verdad, sino que es ella, precisa Heidegger, la que hace ontológicamente posible nuestra existencia de forma que podamos suponer algo. Es la verdad la que hace posible toda suposición. Hasta ahora, en la medida en que la no-verdad se consideraba ajena a la esencia de la verdad en el intelecto divino, todos los modos de la no-verdad: la falsedad, la hipocresía, la mentira y el engaño, la ilusión y la apariencia eran achacables al individuo: "La esencia de la verdad "en sí" reina "por encima" del hombre" (Heidegger, 1943, vol. I, p. 173). Entendemos ahora que la búsqueda de la verdad en Occidente pasa por la culpabilización del individuo. Años antes, Ortega (1914) ya había sugerido que el hallarse oculto no es un rasgo meramente negativo, sino algo que transforma la cosa en algo nuevo.

La esencia de la verdad es la libertad, pero según la metafísica onto-teológica es la libertad una propiedad del ser humano. Sin embargo, no debemos entender la libertad como una opción que el ser humano posee, sino que es ella la que posee al ser humano; no es, como dicta el sentido común, el capricho que surge en nosotros, a veces, de elegir tal o tal cosa. Es el abandono al desvelamiento del ente como tal. Una acción solo puede realizarse por medio de la libertad de quien actúa, como en la acción de re-presentar - no pensemos en una imagen mental sino en una descripción verbal o en un gesto. La verdad nos hará libres, lo que no quiere decir que podamos adoptar decisiones arbitrarias y cómodas, bien al contrario, pues es la libertad la que nos posee, como seres existentes e históricos. Pero el ente también puede ser travestido y deformado. La no-verdad deriva de la esencia de la verdad, no es que simplemente no encaje con ella, sino que puede oponerse radicalmente a ella, no son indiferentes la una a la otra. La exposición plena al ente es un acuerdo afectivo, que sólo puede ser vivido y sentido porque el ser humano se abandona a un acuerdo desvelador con el ser en 
su totalidad. En la libertad se puede realizar también el disimulo del ente, que impide el desvelamiento, al que Heidegger llama aquí "obnubilación" y que está muy próximo a lo que en otro lugar llama "inautenticidad" y que veremos en el siguiente apartado.

De forma más común con la clínica analítica, observamos cómo las mentiras se relacionan con la verdad, por ejemplo, con la negación o denegación (Freud, 1925 h). En la negación (Verneinung), la verdad de lo reprimido (verdrängt, Verdrängung) es de pronto desvelada: "Yo no quiero decir eso" "Usted pensará que le voy a decir algo ofensivo, pero en realidad yo no tengo ese propósito". Freud infiere que lo denegado existe en la mente del paciente y el fenómeno anuncia la posibilidad de superar una resistencia. La renegación o desmentida (Verleugnung), en cambio, es un mecanismo complejo por el que de forma simultánea se reconoce una realidad y se la niega, en concreto, la diferencia anatómica entre varones y mujeres y, consecuentemente, la castración. Esa coincidencia entre renegación y afirmación sólo es posible como bien sabemos si entra en funcionamiento el tercer mecanismo, la escisión (Spaltung). Como advertí en otro lugar (Rodríguez Sutil, 2014) es un mecanismo de defensa pre-neurótico, aunque no propiamente psicótico, al alcance de todo el mundo, pero corriente en los trastornos límites y narcisistas de la personalidad, así como en las perversiones. La verdad es lo no visto, como ausencia será la realidad psíquica, pero en cuanto a algo que queda fuera sólo podrá ser redescubierto como realidad efectiva y externa. Algo que para el psicoanálisis freudiano no tiene lugar (Cf. Ricoeur, 1977).

Un artículo de Kohut (1957) sobre la resistencia incluye un par de ejemplos que permiten ver este mecanismo en la acción interpersonal y formadora del psiquismo:

1) La forma indirecta en que unos padres establecían las prohibiciones: "menos mal que a mi niña no le gustan las galletas",

2) Unos padres que llevan al chico a hacer pis cada vez que tiene el pene en erección, porque supuestamente es lo que necesita.

Como se observa con mayor evidencia en el segundo ejemplo, se trata de un mecanismo que se desliza fuera del nivel del discurso individual e implica la acción física, y no solo el discurso como acción. Estos dos ejemplos poseen la virtud de mostrarnos la renegación no sólo como un mecanismo de la dinámica individual, sino que lo sitúan en el contexto interpersonal. Pensemos en la frustración y disociación que experimentan los respectivos infantes. Aprenden la renegación como modo de ocultar la frustración.

Finalmente, en el repudio o rechazo (Verwerfung), es referido por Freud en uno de sus primeros trabajos (1894a), si bien vuelve a ser citado en otros lugares (1925a), y en el famoso caso $\mathrm{El}$ Hombre de los Lobos (1914, sección VII). En este último texto describe cómo el paciente 
rechazó (verwarf) la percepción de la diferencia anatómica a causa de su intensa angustia de castración y esta reapareció en forma de alucinación. Este mecanismo es usado de forma bastante global para colocar fuera todo el esquema del conflicto. Por ejemplo, un joven que cumplía los criterios de esquizofrenia paranoide, "descubría" intimidades sexuales entre los presentes, en todos los lugares a donde iba, centros de trabajo u ocio, y sin previo aviso obsequiaba a su madre con el siguiente discurso: "El incesto es un delito y yo no estoy dispuesto a cometer ningún delito contigo". La versión ortodoxa del psicoanálisis hablaría del "poner fuera" el conflicto, por ejemplo, para Lacan (Seminario III, 1955-1956), la ausencia dentro del mundo simbólico del significante fundamental (el falo) lleva a que sea alucinado en el mundo exterior, en lo real, lo que explicaría la alucinación del dedo cortado por parte del Hombre de los Lobos. Sin embargo, nada impide que interpretemos el proceso en un sentido inverso: el psicótico se niega a incorporar la versión social del complejo familiar, en nuestra cultura, el Edipo, que se le presenta sin veladura represiva.

Inconsciente es lo que no observamos, o no queremos observar, lo que hacemos 'sin querer'. Nunca está escondido, como la "carta robada" de Poe (Lacan,1956). El inconsciente es aquello a lo que no atiendo o aquello que rechazo, y el afecto queda suelto, como ese mal sabor de boca cuya causa ignoramos. Algo que, como hemos visto puede no haber sido todavía descubierto, o puede estar enterrado. Inconsciente es también lo que queda tácito en nuestro intercambio comunicativo.

Elena, una paciente en la mitad de la cincuentena, se sentía inferior y sufría al no sentirse valorada por sus padres, especialmente por su madre. Nacida tardíamente cuando sus padres no la esperaban, se sentía relegada históricamente respecto a su hermana, Cristina, diez años mayor. Esta siempre era tomada como ejemplo por sus resultados en los estudios y atractivo físico. Ella, sin embargo, logró terminar estudios superiores - aunque no se ha atrevido a buscar un puesto acorde con sus cualificaciones - mientras que la hermana fracasó en la universidad. Aunque ambas trabajan y están casadas y con hijos, al ser los padres mayores y necesitar cada vez más apoyos externos, es Elena la se ve obligada a dedicar gran parte de su tiempo libre a cuidar de ellos. Cuando se ve la necesidad de resolver trámites administrativos, ella va a las entrevistas y recoge los documentos, aunque es la hermana la que termina las gestiones por el puesto que desempeña en la comunidad. Sin embargo, Elena se topa con numerosas dificultades para reunirse con Cristina. Siempre está ocupada por obligaciones laborales o personales y la cita en horarios poco propicios, o la hace esperar mucho tiempo para luego despacharla en "pocos minutos". Con una complicidad impensable en una perspectiva ortodoxa, y tirando de una forma moderada de autodesvelamiento, el terapeuta se siente identificado con la paciente, y molesto con la hermana, y utiliza la metáfora tomada del baloncesto: "los minutos de la basura". Elena pregunta qué significa esa expresión. Cuando 
un partido está ya decidido porque existe mucha distancia entre la puntuación de uno y otro equipo, se ven obligados a continuar los últimos minutos, aunque ya no sirvan para resolver nada. Elena se siente impresionada por la imagen y en esa sesión y en otras posteriores revisa su historia personal y familiar desde una perspectiva diferente. Cambia la relación con sus padres, pero, sobre todo, con la hermana, de forma muy positiva para su autovaloración.

Este es un ejemplo de descubrimiento por parte de ambos integrantes de la diada terapéutica en la que ambos han compartido una vivencia. Desde una perspectiva más clásica se podría decir que lo que se había elaborado no estaba tanto en relación con representaciones reprimidas como con rasgos de carácter, hasta ese momento no examinados, que se actuaban de forma procedimental.

El límite entre consciente e inconsciente es flexible - algo contrario a la concepción tradicional de "barrera represiva" - y viene determinado por el contexto intersubjetivo específico (Stolorow y Atwood, 1992, p. 70 y ss.). Todas las formas de inconsciente se derivan de contextos formativos relacionales específicos. Lo inconsciente, diremos, se crea en la relación y es, como mínimo, bi-personal, se establece entre dos personas - o más, pues también nos parece legítimo hablar de un inconsciente grupal, o familiar -. Aún el funcionamiento del psiquismo inconsciente individual es social por naturaleza (Mitchell, 1988, 1993, 2000; LyonsRuth, 1999; Gerson, 2004). En un sentido más amplio, la mente no surge de presiones internas, sino que desde el origen es diádica (dos o más personas) e interactiva, busca el contacto, el engranaje con otras mentes (Mitchell, 1988, p. 15). Indudablemente, la relación con el otro que forma el psiquismo es dialéctica, en el sentido de oposición de contrarios y de lucha radical por el reconocimiento (Benjamin, 1996).

En la medida en que el psicoanálisis relacional preconiza la superación de términos estáticos como transferencia, contratransferencia, resistencia - que transmiten la idea de una difícil comunicación entre dos mentes o compartimentos estancos, y se prefiere hablar de la sesión analítica como un campo de interacción, un espacio transicional, de terceridad, algo "cocreado" por analista y analizando en un proceso de mutualidad, en esa medida, decimos, el concepto de verdad, como descubrimiento, es aquello nuevo que surge y se descubre entre dos personas en relación (Cf. Espinosa et al., 2005; Velasco, 2005). De hecho, la interpretación productiva o transformadora no será sólo la que se corresponda con la realidad (Wirklichkeit) mental del paciente, sino la que permita un descubrimiento de la realidad "objetiva" o histórica (Realität) aunque inicialmente no fuera acertada. Esto no supone un gran acercamiento a los criterios empíricos de prueba, por cuanto esa realidad "objetiva" recién descubierta no deja de ser una construcción en el aquí y ahora de la situación de terapia, no fácilmente contrastable con una verdad externa, no es algo "mental", en el sentido de 
"individual", pero tampoco se confunde con una realidad física, pasible de ser medida, sino con el sentido de la relación. La verdad que se descubre en la relación terapéutica es también algo construido o co-creado por paciente y terapeuta que solo tendrá validez y duración en la medida que sea un descubrimiento que surja como verdad narrativa de la relación y de relaciones pasadas. Pensemos en el contexto relacional del trauma tal como lo caracterizaba Balint (1979), que aparece con frecuencia explicitado en la clínica, pero difícil de reducir a un registro empírico positivista como el que desearía Grünbaum:

- Un niño depende de un adulto de confianza

- Ese adulto demuestra ser indigno de confianza, mediante la sobreestimulación, la negligencia o el rechazo del niño

- El niño trata de obtener alguna comprensión, reconocimiento y consuelo del mismo adulto.

- El adulto a menudo niega la perturbación, culpa al niño del trastorno y le niega la confianza

Dice Winnicott que si interpreta es para que el paciente tenga noticia de los límites de su comprensión (del terapeuta) (Cf. Sainz, 2017). La comprensión absoluta también es imposible. Cuando la interpretación va más allá de lo que es comprensible por el paciente y que éste alcanzaría solo, se transforma en algo invasivo, en adoctrinamiento, y fomenta el aislamiento y la resistencia, aunque superficialmente pueda producir admiración. La buena terapia está guiada por la mutualidad, cuyos elementos fundamentales son una conversación franca y la autenticidad. En el trabajo con niños esta mutualidad se muestra de manera nítida en el juego del garabato (squiggle game) de Winnicott, proceso de juego creativo en el que participan los dos: uno hace un garabato y el otro lo completa, alternativamente.

Hans-Georg Gadamer (Grondin, 1991; Gadamer, 1960, 1975; Orange, 2010) entiende la hermenéutica como un proceso de comprensión mediante el diálogo con el autor de un texto o con un interlocutor, diálogo del que surge algo que es único e inesperado. Cuanto más auténtica es la conversación, menos posibilidades tienen los interlocutores de "llevarla" en la dirección que desearían. Nos enredamos en una conversación y lo que sale de ella nadie lo puede saber previamente, cada participante intenta convencer al otro, pero también escucha con atención lo que el otro le puede enseñar, rechazando toda forma de comunicación autoritaria, en la que a veces se convierte el psicoanálisis. Esta hermenéutica de la confianza, en oposición a la "hermenéutica de la sospecha" requiere un psicoanálisis no autoritario ni ideológico que dé la bienvenida al otro en la conversación (Cf. Orange, 2010). Debemos acercarnos a toda conversación esperando y deseando aprender algo de nuestro interlocutor. 
$\mathrm{Si}$, en cambio, la hermenéutica fuera simplemente interpretación unilateral del otro, habríamos evitado las explicaciones biologicistas, pero nos deslizaremos hacia a un idealismo de las interioridades mentales. El lenguaje no se practica a modo de enunciados sino con preguntas y respuestas que, a buen seguro, no surgen en un campo lógico sino experiencial, en la relación de dos o más personas, en el que terapeuta y paciente se ocupan del otro.

Según el modelo clásico, el síntoma es la expresión de un compromiso del yo con las otras tres instancias (ello, super-yo y realidad). El síntoma es un retorno de la verdad, está estructurado como un lenguaje, un lenguaje cuya palabra debe ser liberada (Lacan, 1953 a). Sigue el modelo de la metáfora, porque en él se muestra la sustitución de un significante reprimido por otro corporal (Lacan, 1954). En lenguaje lacaniano se diría que el síntoma neurótico cumple la función de gozo sustitutivo y de expiación inconsciente de la culpa, y que se produce por la influencia de lo simbólico en lo real (Lacan, 1974). Esta culpabilidad necesaria del neurótico puede ser de origen endógeno, postura del psicoanálisis clásico, con un supuesto fundamento filogenético (Freud, 1912-13; 1939 a). O bien ser exógena, por el aprendizaje de las normas morales en el contexto familiar. Estamos de acuerdo en que el síntoma es una forma de comunicación entre las personas. Sirve para solucionar un problema emocional y expresar un sufrimiento. Pero no siempre está estructurado como un lenguaje, no siempre se muestra como una simbolización o enunciación del conflicto, como en la conversión histérica, sino que adopta la expresión presimbólica, procedimental, de los hábitos de relación que no se interpretan, sino que se descubren. La terapia se configura como un trabajo conjunto para compartir y comprender el sufrimiento y buscar las soluciones más creativas y que permitan un mejor crecimiento o libertad. Con el paradigma relacional, repetimos, la interpretación deja de ser es el instrumento terapéutico fundamental, y se concede una mayor relevancia en la producción del cambio la presencia empática del terapeuta, el acompañamiento, el sostén - según Winnicott (holding) (1956; Cf. Abello y Liberman, 2011)-.

La sesión analítica se diferencia de cualquier otra conversación en cuanto a que una de las partes (el paciente) se presenta como ser humano que sufre para hablar con otro ser humano que está dispuesto a poner entre paréntesis su propio sufrimiento para indagar juntos sobre el sufrimiento del primero, buscar y descubrir su esencia y ver la forma de aliviarlo.

\section{Verdad como autenticidad}

Para el hebreo, señala Ferrater Mora (1986), la verdad esencial es el cumplimiento de la promesa, y suponemos que la amenaza es también una forma de promesa. Lo contrario de la verdad es la decepción, en tanto que lo contrario de la verdad para la aletheia griega es la desilusión. Si bien se mira, en la relación terapéutica también se da un cumplimiento, 
entendido como el cumplimiento de un compromiso. El terapeuta y el paciente se comprometen a seguir las consignas y a la mutua sinceridad. El terapeuta se compromete a acoger a su paciente y a intentar ayudarle, en la medida de lo posible, en su proceso de cambio, y en esa relación, de hecho, ambos deben estar abiertos al cambio. No obstante, en la relación analítica ya no puede haber una neutralidad estricta, y una asimetría como inicialmente se postulaba, aunque no por eso lleguemos a una simetría completa (Aron, 1996). El paciente no siempre está equivocado cuando muestra su desacuerdo con algo que el terapeuta ha dicho o hecho, y en ocasiones es necesario que el terapeuta adopte una posición de "autodesvelamiento" (self-disclosure) para descubrir de donde viene el error. Por ejemplo, en determinadas circunstancias, el terapeuta comunica al paciente cómo se ha podido sentir por algo que el paciente ha dicho o hecho, o bien planteando la hipótesis de cómo se habría sentido en el lugar de otra persona en una escena que relata. Esto puede facilitar a la persona el captar los efectos de su conducta produce en los demás y el significado de dichos efectos.

Donna Orange (2010) propone una aproximación a la terapia guiada por la ética del filósofo francés Emmanuel Levinas, autor muy influido por Heidegger y por el Talmud, mezcla en principio sorprendente. Frente a la actitud de o tratar al otro como algo que debe ser estudiado, Levinas plantea el valor del "rostro", el modo en el que el otro se me presenta, cara a cara, desbordando la idea que existe en mí de ese otro, en su infinita demanda de protección y cuidado. Esa cara dice: "no matarás" y "no me dejarás morir solo". La relación con el prójimo produce una "curvatura del espacio intersubjetivo", porque la relación ética es asimétrica. La responsabilidad que el rostro del otro pone en mí - sugiere Levinas - coloca al ser humano es una relación ética que excede todo conocimiento y todo uso, así como toda racionalidad técnica. Kant sugería, en su segunda definición del imperativo categórico, que debemos tratar al otro como un fin en sí mismo, no como un medio. Por eso el diálogo excluye toda explotación objetivante $y$, dicho sea de paso, toda técnica y todo diagnóstico.

Acaso de manera menos radical, era algo parecido lo que proponía Winnicott (1969) con su concepto del "uso del objeto" y la conveniencia de que el terapeuta se ofrezca para ser usado. En la relación de objeto, el sujeto permite que se produzcan ciertas alteraciones en la persona, pero si se quiere usar al objeto, es obligatorio que el objeto sea real, como realidad compartida, y no un manojo de proyecciones. El terapeuta se ofrece a ser usado e intenta sobrevivir al uso, a los ataques del paciente, como la madre suficientemente buena sobrevive a los ataques destructivos del bebé, reconociendo la propia agresividad en la contratransferencia. Ahora bien, es importante señalar que existe una notable diferencia entre que el analista sea usado como objeto o que sea explotado como persona. El paciente no necesita un santo como analista, necesita autenticidad. 
Volviendo a Heidegger (1927), cuando elegimos interpretar nuestro ser en una forma general, adaptada al público, viviendo en el mundo del "uno", haciendo "lo que uno hace", comportándose como "uno se comporta", porque es "lo correcto", o lo más cómodo, caemos en la forma de ser inauténtica $(1927, \$ 37)$. Se trata de un refugio en la generalidad que evita la búsqueda, a menudo dolorosa, del sí mismo. Un refugio porque sirve para protegerse de la angustia (1927, \40). Este concepto heideggeriano de inautenticidad guarda, sin duda, un gran parecido de familia con el falso self según Winnicott (1965). El falso self es como una cáscara protectora que se procura el niño - y conserva el adulto - cuando no ha sido adecuadamente sostenido, es una protección frente a la indefensión provocada por fracasos primarios, es decir catastróficos. El verdadero self queda entonces oculto, así como algunas facetas del crecimiento emocional, por temor a frustraciones masivas, y el niño logra proseguir de alguna manera con su evolución. Como sintetiza Françesc Sainz (1917):

El falso self es un protector del self, lo protege como si de un niño indefenso se tratara, lo esconde en la guarida y le viene a decir que él (el falso) dará la cara por él (el verdadero). A la vez que lo oculta, tampoco lo deja existir; es como si unos padres escondieran a su hijito para protegerlo de los daños de la vida, pero a la vez no le dejaran experimentarla. (p. 66)

Ampliando el campo, pensemos en el "esquizoide", al que alude Fairbairn (1940), quien sólo se permite amar y ser amado desde lejos, un método para proteger simultáneamente a los objetos internos y externos. Representa roles, sin llegar a creérselos, o se dedica al exhibicionismo, una forma de dar sin dar. El falso self se refiere, por tanto, a un estilo de comportamiento falso, pero con frecuencia necesario para la supervivencia en las etapas tempranas.

Freud recomendaba al analista mostrar sólo aquello que le es mostrado y comparaba esta actitud con la función de un espejo, metáfora que ha tenido un significativo éxito en la historia del psicoanálisis. Se ha aludido a ella con frecuencia como garantía de la neutralidad del terapeuta y confirmación del principio de abstinencia; según este principio un alivio prematuro de los padecimientos del analizado entorpecerá la buena marcha del tratamiento, que a partir de ese momento no proporcionará más que mejoras parciales y pasajeras. Se supone que la frustración analítica, producida por el principio de abstinencia, lleva al sujeto a adoptar modelos de conducta del pasado, cada vez más "seguros" (la transferencia). Sin embargo, para superar el falso self, para alcanzar la autenticidad, las personas individualmente y en grupo deben asumir riesgos, en una frontera con la ética que no se suele indagar en los textos clínicos. Asumir la verdad es muy a menudo un riesgo, el riesgo de abandonar la neutralidad y - según Donna Orange - de tomar partido por el paciente. 
El hombre tiene la posibilidad de negar su naturaleza animal empírica, puede querer su muerte, arriesgar su vida, en sentido hegeliano. El ser negativo es esencialmente finito. Sólo se puede ser hombre si se puede morir. Hace falta estar dispuesto a morir como un hombre para ser un hombre. La muerte debe ser aceptada libremente; debe ser una muerte violenta en un combate. El individuo debe arriesgar su vida para forzar la conciencia del otro, debe arriesgar su vida para hacer reconocer su personalidad, pero no es como un cadáver como quiere ser reconocido. Y si lo que busca es matar a los otros, no es por cadáveres por quienes puede y quiere ser reconocido. El reconocimiento mutuo es el punto más vulnerable del proceso de diferenciación. Para existir para uno mismo es preciso existir para otro, pero si destruyo al otro, no habrá nadie que me reconozca. Si no le permito ninguna conciencia independiente quedo enredado con un ser muerto, no consciente. Jessica Benjamín desvela lo que se halla implícito en Hegel: "La verdadera independencia supone mantener la tensión esencial de estos impulsos contradictorios; es decir, tanto afirmar al sí-mismo como reconocer al otro" (1988, pág. 73). La pérdida se compensa por el placer de compartir, por la mutualidad. Ninguna persona puede ser una pantalla totalmente en blanco. El terapeuta es algo más que una pantalla sobre la que el paciente proyecta sus fantasías, o un instrumento neutro para la técnica interpretativa; su personalidad y sus motivos suponen una contribución significativa al proceso terapéutico. La tradición psicoanalítica predominante presentaba la neutralidad y el principio de abstinencia como algo irrenunciable, unido a la inevitable asimetría que traza la situación analítica, entre un terapeuta, previamente analizado, conocedor y controlador de su inconsciente, y un paciente desconocedor absoluto de sus motivaciones profundas, que debe rendirse ante el criterio del primero. Como advierte Ávila (2005), la neutralidad y la asimetría extrema son las que hacen surgir fenómenos notables de transferencia que desgraciadamente dejan fuera de nuestro campo de observación lo que es la auténtica relación terapéutica. Bromberg (2011) insiste en la importancia de comunicar al paciente la preocupación personal sobre los efectos que tiene en él lo que uno está haciendo, incluyendo el efecto de compartir los sentimientos con él. De esta forma el paciente sabe que estás pensando sobre su seguridad afectiva mientras desempeñas tu tarea.

En esa línea, desde la actual psicología del self, en lugar del principio de "abstinencia" se prefiere hablar de "responsividad óptima" o la "especificidad", es decir, la práctica debe priorizar la especificidad del momento, respondiendo de una manera $u$ otra ante el paciente (Bacal, 2017; Bacal y Carlton, 2017). El terapeuta que funciona en el registro de la responsividad óptima tiene en cuenta tanto los marcadores o señales que el paciente da de lo que espera de las respuestas del terapeuta, como las reacciones del paciente a las respuestas percibidas. Estas señales, presentes desde los primeros contactos, dan información muy valiosa sobre las necesidades de relación ("objeto sí mismo") que no han sido satisfechas por 
los cuidadores anteriores. La relación terapéutica debe entenderse como una segunda oportunidad para el desarrollo emocional, dentro del proceso analítico, como una relación desconfirmadora de lo patógeno, con las características de un vínculo fundante complementario (en el sentido de la teoría vincular) (Ávila, 2013). Cada paciente y cada momento terapéutico requerirá un grado diferente de responsividad por parte del terapeuta, que evite en todo momento los riesgos de explotación del paciente o de satisfacción narcisista del terapeuta:

La práctica basada en la teoría de la especificidad implica centralmente un proceso de descubrimiento de respuestas que pueden ser efectivas terapéuticamente para un paciente particular, pero sin el uso de unas prescripciones o guías prescriptivas, aunque surjan hipótesis tradicionales de la estructura, que sean de utilidad. Cuando somos capaces de captar lo único y específico de cada encuentro terapéutico, podemos implicarnos continuamente en el momento para determinar cuál es la respuesta terapéutica necesaria, y qué nos es posible ofrecer para cada ocasión. (Bacal, 2017, p. 23)

La fusión de los conceptos de neutralidad y abstinencia puede haber contribuido a crear una imagen estereotipada del analista rígido y reservado, pero se trata de una interpretación equivocada de lo que Freud realmente sugería, error producido al tomar un principio por una regla (Killingmo, 1999). La idea de la abstinencia, como principio general y como instrucción respecto a la conducta social, ha provocado una gran confusión, debiendo ser reubicada en su papel de principio general y rechazarse definitivamente su vinculación con la imagen del analista frío y carente de empatía.

El hombre es plenamente hombre, considera Ortega (1947) - en una conferencia de gran relevancia para el terapeuta que lo desee entender - cuando se esfuerza en saber, en hacer que nuestro pensamiento coincida con el ser de las cosas, que no lo tienen ellas por sí solas sino cuando una persona se encuentra ante ellas, tiene que habérselas con ellas $y$, en esa medida, debe saber qué hacer con ellas y qué puede esperar. Nos adaptamos a todo menos a no tener clara nuestra posición respecto a lo que creemos de las cosas. Aunque hable de un saber, Ortega no se está refiriendo a una actitud intelectual y, por tanto, distante respecto a lo que nos rodea:

Algo me es problema no porque ignore su ser, no porque no haya cumplido mis supuestos deberes de intelectual frente a ello, sino cuando busco en mí y no sé cuál es mi auténtica actitud con respecto a ello, cuando entre mis pensamientos sobre ello no sé cuál es rigorosamente el mío, el que de verdad creo, el que coincide conmigo. (id., pp. 109-110)

El auténtico problema es encajar yo en mí mismo, encontrarme en mí mismo. He sido lanzado a la circunstancia caótica de las cosas, donde me pierdo porque me sacan de mí, me convierten 
en otro. La solución de dicho extravío es volver a coincidir conmigo mismo, tener clara cuál es mi sincera actitud ante cada cosa. $Y$, para reforzar ese matiz de no intelectualidad que apuntábamos, Ortega sugiere que el campesino más humilde puede estar tan en claro sobre sus reales convicciones sobre el limitado ámbito de cosas que componen su circunstancia que apenas tenga problemas y viva su vida con total serenidad. En cambio, el que sabe muchas cosas puede perderse "en la manigua de sus propios saberes" (id., p. 111). Se habitúa a vivir en pseudocreencias y en lugares comunes, a veces muy sofisticados pero que falsifican su existencia. El ser humano para vivir tiene que pensar, quiéralo o no, pero no es obligatorio que se convierta en un intelectual. Si no vivo de acuerdo con mi pensamiento sufriré angustia. Si piensa bien, encajará en sí mismo, y esa es la definición de la felicidad. Pero no debemos caer en el error de que si pensamos de otro modo ya pensamos como queremos:

La misión superior del hombre no es ser agudo, sino simplemente resolver su vida lealmente, sinceramente. (id., p. 115)

Que nos recuerda la sentencia de Sullivan: "Dios me libre de un psicoanalista listo" (Cf. Levenson, 1912, p.3).

El siguiente caso nos enseña que para ser sincero consigo mismo no se necesita pertenecer a una escuela concreta, como no se necesita ser kohutiano para trabajar con la empatía. Ralph Greenson (1967), psiquiatra norteamericano de origen suizo que se hizo famoso como psicoanalista de Marilyn Monroe y de otras estrellas de Hollywood de la época, también aportó un importante texto sobre técnica analítica - desde la llamada "psicología del yo" - que todavía pueden leerse con gran provecho. En su libro sobre Técnica y Práctica del Psicoanálisis, en el capítulo que dedica a la técnica del análisis de la transferencia, nos cuenta el caso de un paciente que entró en lo que denominaríamos una fase de impasse o punto muerto, se volvió más callado y huraño y sólo colaboraba formalmente con la labor analítica. Finalmente, un día confesó su frustración por haber querido adoptar posturas políticas liberales, más cercanas a las preferencias demócratas de analista, cuando él era un republicano convencido. Sorprendido por esta observación, Greenson le preguntó cómo es que había llegado a la conclusión de que él era de preferencias demócratas, a lo que el paciente respondió que cuando decía algo positivo de un político republicano, él siempre le pedía asociaciones, y que cuando decía algo negativo, callaba como asintiendo. Igualmente, cuando atacaba a Roosvelt le pedía asociaciones, para ver a quién le recordaba, mientras que los comentarios positivos eran aceptados sin réplica. Esta historia ilustra la idea de que el paciente es un intérprete, a menudo perspicaz, de la experiencia del analista. Greenson, con muy buen criterio y como ejemplo de su integridad, se sintió obligado a reconocer cuán acertado estaba el paciente en la apreciación de sus preferencias políticas 
Frente a otros principios del psicoanálisis clásico, propongo el principio de veracidad, para categorizar la conducta que consideramos adecuada, se trabaje desde el enfoque terapéutico que se quiera. Este principio vendría a decir que el paciente debe ser atendido con la mayor veracidad posible, dentro de la prudencia y la razonable firmeza que podamos tener en esos conocimientos, cuando inquiera sobre aspectos de su propia persona, pero también de la nuestra en la medida en que estos se hallen implicados en la terapia. $Y$ esta intervención deberá ser antes descriptiva que interpretativa. A menudo me parece exigible responder a cuestiones que tienen que ver con mis propias opiniones o creencias sobre cuestiones fundamentales, como pueda ser mi orientación teórica en psicoanálisis al igual que, sin extenderme en detalles, cuando se trata de religión o política, y entiendo que una buena disposición a la ayuda sólo puede partir de mantener posiciones moderadas y tolerantes en estos dominios. La mejor forma de evitar una influencia coercitiva no es eliminar los propios valores y la propia visión de la realidad, sino hacerlos lo más explícitos posible. Ahora bien, con frecuencia es un ejercicio fecundo, por no decir asombroso, preguntar antes al paciente qué idea previa se hace él respecto a nuestra postura.

Los libros sobre técnica y supervisión nunca serán el referente definitivo ni más importante que guíe nuestra labor, sino que - parafraseando de nuevo a Alejandro Ávila (2005) - son las historias que vivimos con nuestros propios pacientes las que nos deben mover a la reflexión sobre la actitud que adoptamos en nuestra tarea y en qué medida somos sólo o principalmente instrumentos de una cura que opera desde la neutralidad o agentes de un proceso complejo que se despliega en un horizonte de relación, implicación y mutualidad. Aventurarnos más allá de la neutralidad y la abstinencia, con el debido respeto a la individualidad de nuestros pacientes y de nosotros mismos, no sólo no nos ha traído las nefastas consecuencias que algunos auguraban, sino que nos ha abierto un panorama de gran riqueza teórica, técnica y humana.

El término "resistencia", entendido sólo como la resistencia del paciente, es una justificación del punto de vista del analista. La resistencia es una evitación de algo, de una realidad, que supone la interferencia en el aquí y ahora del allí y entonces. Este punto de vista, que incorpora la necesidad de comprender tanto el pasado como el presente, ha llevado a algunos autores a proponer que es la resistencia, y no la transferencia, la que es co-construida. El objetivo del tratamiento analítico es, dice Renik (1995), proporcionar un beneficio terapéutico aumentando la autoconciencia del paciente. Por lo tanto, resistencia será todo aquello que interfiera con este incremento de la autoconciencia. La resistencia más pertinaz es la que depara un análisis sin dirección: el paciente dice lo que le viene a la mente y el analista le ofrece sus reflexiones, pero sin que ninguno de los dos se plantee hacia dónde va el proceso. Esta falta de efectividad nos muestra que la falta de autenticidad también tiene consecuencias de 
tipo pragmático: no cambia nada y de nada sirve. El análisis es una tarea dirigida a fines, según Renik, el fin esencial es el aumento de la autoconciencia. Opino que no siempre es así, el análisis también puede reportar beneficios que se sienten y se muestran en la vida cotidiana, aunque no se puedan explicar y su mecanismo subyacente esté más allá de la conciencia. El paciente vive una experiencia correctora al ser atendido con genuino interés por alguien que le valora de forma positiva, pero no ciega.

\section{Conclusiones}

En la sesión analítica, una de las partes (el paciente) se presenta como ser humano que sufre para hablar con otro ser humano que se ofrece para buscar alivio juntos. La noción de inconsciente es, cómo no, de suma utilidad en esa indagación. El inconsciente freudiano podría equipararse con el fenómeno, el ocultarse y desvelarse del ente, como tal vez sugiere el concepto de serie complementaria (1938b, p.3387 y ss.). La tarea que se propone el psicoanálisis freudiano consiste en hacer que coincidan las dos "versiones" o "registros", volver consciente lo inconsciente. De esa forma se establece "una serie complementaria consciente para lo psíquico inconsciente". El instrumento clásico de dicha indagación, como ya sabemos, es la interpretación, y su contrapartida subjetiva que es la mirada hacia adentro (Einsicht) en el curso de la asociación libre. Descartes y el introspeccionismo quedan lejos pues la conciencia deja de ser el acceso privilegiado a nuestra realidad. La asimilación de todo lo psíquico a la conciencia es un error, porque deja fuera gran parte de la realidad observable. Sin embargo, a la larga se dota a lo inconsciente de cualidades semejantes de interioridad y ocultamiento. En Maclntyre (1958, p. 103) se encuentra plasmada esa idea: "... sería como reduplicar la mente sustancial consciente de Descartes con una mente sustancial inconsciente". Y añade "Lo inconsciente es el fantasma de la conciencia cartesiana".

Por tanto, lo inconsciente freudiano debe ser planteado no como una entidad sino como una característica de los procesos psicológicos, más acusada en unos casos que en otros. Por la misma operación, la conciencia debería dejar de ser un espacio o entidad para convertirse en una cualidad del acto psicológico, y de la misma forma desaparecerían rasgos y estructuras internas. Una afirmación es verdadera si concuerda con el conjunto o el modo de representación de la realidad y, en definitiva, con la forma de vida. Una reconstrucción narrativa es acertada en su globalidad porque no es posible atribuir significado a un signo o proposición aislados - el "esto es un 'perro'", de las definiciones ostensivas -. El conjunto de las proposiciones, el sistema, cobra sentido como forma de adaptación a una realidad compleja, a una forma de vida: un estilo en nuestra forma de estar en el mundo de manera íntegra y genuina, lo que no quiere decir que desaparezcan automáticamente todas las 
contradicciones. Y esta verdad como forma de vida e integridad no es cualitativamente diferente del descubrimiento o desvelamiento: una proposición será verdadera cuando nos descubra algo relevante sobre nuestro modo pragmático de inserción en la realidad.

Si, como afirma la teoría del apego, la primera necesidad es el contacto humano, el concepto "biológico" al que deberemos recurrir es la forma de vida como totalidad narrativa del ser humano en su contexto, la totalidad de la cura. Este método psicoanalítico-hermenéutico tendrá por principio la integración de las vivencias en su conjunto. Por lo demás, no es necesario mantener la teoría pulsional para suponer que los traumas tempranos producen un deterioro o déficit en el funcionamiento interpersonal del individuo. Hemos argumentado que la recuperación en alguna medida de la teoría traumática nos libra de la energética intrapsíquica.

En el psicoanálisis relacional una consecuencia del abandono del modelo de la mente aislada es la reducción de la asimetría en la relación paciente-terapeuta, que se convierte en una relación de mutualidad, con el conocimiento recíproco de la experiencia que comparten y de la mutua influencia que ejercen el uno sobre el otro, reconociendo cada uno la subjetividad del otro: "La psicoterapia es un diálogo entre dos universos personales, un diálogo que transforma a ambos" (Atwood, 2014). De esta forma el paciente pasa a ser un interlocutor válido, con quien debemos tener una profunda implicación emocional para intentarle ayudar, utilizando las técnicas que se consideren útiles, aunque no todas superen las pruebas de lo estrictamente analítico. La aportación fundacional del análisis a la que no renunciaremos es la de sentarnos delante del paciente a escuchar lo que tiene que decir. Se ha sugerido a veces que el psicoanálisis relacional presta una atención y un respeto especial por la subjetividad del otro. Estoy de acuerdo con eso, siempre que por subjetividad entendamos la persona total, no sólo lo que enuncia explícitamente, ni sus "contenidos mentales", sino lo que dicen (y lo que callan) paciente y analista, desde su contexto total pasado, presente y futuro, y en el campo interpersonal de la terapia analítica.

La verdad no reside en la cabeza de una sola persona, sino que está entre las personas, aquellas que la buscan en sociedad, reunidas por Sócrates que les convocaba para discutir y la hacía surgir con sus artes de partero, si bien como algo que se construye, no que nace ya hecho (Bajtín, 1979, p.222). Esta definición de la verdad sería sin duda aceptada por la filosofía hermenéutica de Gadamer (1960), que entiende la hermenéutica como un proceso de comprensión mediante el diálogo del que surge algo que es único e inesperado:

Acostumbramos a decir que "llevamos" una conversación, pero la verdad es que, cuanto más auténtica es la conversación, menos posibilidades tienen los interlocutores de "llevarla" en la dirección que desearían. De hecho, la verdadera conversación no es nunca la que uno habría 
querido llevar. Al contrario, en general sería más correcto decir que "entramos" en una conversación, cuando no que nos "enredamos" en ella. Una palabra conduce a la siguiente, la conversación gira hacia aquí o hacia allá, encuentra su curso y su desenlace, y todo esto puede quizá llevar alguna clase de dirección, pero en ella los dialogantes son menos los directores que los dirigidos. Lo que "saldrá" de una conversación no lo puede saber nadie por anticipado. El acuerdo o su fracaso es un suceso que tiene lugar en nosotros. (p. 104)

Ahora bien, desde la perspectiva del observador - aunque pretenda observarse a sí mismo - si la hermenéutica fuera simplemente interpretación unilateral del otro, del texto producido por el otro, habremos evitado las explicaciones biologicistas, pero nos deslizamos a un idealismo de las interioridades mentales. Ese idealismo que - según Bajtín (1979, p. 177) - conoce sólo un tipo de interacción cognoscitiva entre conciencias: la enseñanza que imparte un conocedor que posee la verdad a aquel que no la conoce y que está en el error, entre maestro y discípulo o, añadimos, entre analista y paciente, por consiguiente, un diálogo pedagógico. Este diálogo no tiene por qué estar ausente de la relación terapéutica, pero nunca deberá sustituir la búsqueda desde la mutualidad.

Para Platón el pensamiento es el diálogo del alma consigo misma. Es diálogo porque consiste en preguntas y respuestas, uno se pregunta a sí mismo como podría preguntarle a otro. En consecuencia, el lenguaje no se practica a modo de enunciados sino con preguntas y respuestas que, a buen seguro, no surgen en un campo lógico sino experiencial, en la relación de dos o más personas, en el que terapeuta y paciente se ocupan del otro. La hermenéutica gadameriana es una puesta en cuestión radical de la ideología implícita en la teoría y la práctica del psicoanálisis tradicional. Rechaza toda forma de comunicación autoritaria, si bien reconoce la autoridad de la tradición; desenmascara toda pretensión de interpretación experta, así como la noción de empatía como la capacidad de leer la mente del autor o del paciente y es una teoría de la comprensión emergente y autocorrectiva. La fusión de horizontes (Horizontverschmelzung) se produce sólo si ambos interlocutores están dispuestos a arriesgar sus prejuicios, principios organizadores, convicciones emocionales o, en las propias palabras de Gadamer, "expectativas vinculantes". Esta hermenéutica de la confianza, en oposición a la "hermenéutica de la sospecha" que Ricoeur atribuía a Marx y a Freud, requiere un psicoanálisis no autoritario ni ideológico que dé la bienvenida al otro en la conversación. La tarea de ayudar a que el otro se comprenda a sí mismo nos puede liberar de aquello que nos tiene prendidos sin haber sido nunca cuestionado. Debemos acercarnos a toda conversación esperando y deseando aprender algo de nuestro interlocutor. Comprendemos desde una perspectiva histórica o, para nosotros como clínicos, matiza Orange (2010, 2011), evolutiva. Necesitamos la tradición para poder comprender o interpretar cualquier cosa, lo mismo que 
la historia personal es imprescindible en el trabajo psicoanalítico para lograr la recuperación y el progreso.

El enfoque relacional, ya incluso desde la teoría de las relaciones objetales, otorga mayor relieve a las experiencias negativas tempranas, procedentes del ambiente, que han causado la patología, lo que supone una recuperación parcial de la teoría traumática - recuperación que ya comenzó Sándor Ferenczi (1932) - y un interés creciente en la investigación sobre el desarrollo infantil temprano, puesta de gran actualidad desde los trabajos de Daniel Stern (1983). En la terapia buscamos la narración no en tanto mera creación intrasubjetiva del paciente, sino integrando significativamente esas situaciones traumáticas y esos influjos iniciales del desarrollo, que intervienen no sólo como contenidos reprimidos sino también en la propia constitución de nuestro ser corporal y nuestros hábitos.

A Zeljko Loparic (1999) filósofo brasileño nacido en Croacia, debemos algunas sagaces observaciones sobre algunas implicaciones de la concepción de Winnicott - quien no era muy explícito sobre sus ideas más teóricas - que se apartan del pensamiento naturalista - es decir, de la metapsicología - y lo convierten en un constructor desconocido - quizá hasta para sí mismo - pero fértil del Daseinanálisis heideggeriano. La noción de Winnicott sobre el ser humano y su proceso de convertirse en persona no sólo difiere de la de Freud sino, más importante, también del modelo metafísico tradicional. En la metafísica tradicional no tiene sentido hablar del hombre como un lugar en el que tiene lugar el ser y que reemplaza al noser. Desde Platón - comenta Loparic - sólo se ha hablado del no-ser via negationis, considerándolo como una privación de ser, sin conceder al no-ser una dimensión original independiente. Winnicott, en cambio, concibe al ser como surgiendo de la nada y no como siendo creado a partir de la nada, porque la idea de creación preserva la preeminencia del ser o de la presencia sobre no-ser y la ausencia. Forma de pensar post-metafísica. El niño construye su identidad a partir de la relación simbiótica con la madre - donde la madre obtiene simultáneamente su identidad en tanto que madre - y esa identidad no viene prefigurada en la genética. En esto también veríamos concordancia con la idea de juegos de lenguaje de Wittgenstein; juegos como los que se usan para enseñar a los niños la lengua materna, que son completos, ya desde el principio, y se aprenden dentro de un contexto pragmático interpersonal. Los conceptos se aprenden en redes, no individualmente, y el niño debe 'saltar' dentro de una red caracterizada por cierto tamaño y cierta estructura lógica, sin atravesar estados intermedios en los que la red fuera menor (Cf. Woodfield, 1987).

Como resumen del camino recorrido podemos concluir que la escisión del psicoanálisis como cura y como búsqueda de la verdad es en gran medida artificial. La cura pasa irremisiblemente por un contacto humano empático y una relación de mutualidad, y sólo puede permitir un 
cambio positivo en el paciente en la medida en que ese contacto y esa mutualidad sean verdaderos, es decir, sinceros. El planteamiento lacaniano - y también freudiano - nos da una versión excesivamente individualista e intelectualizada de la búsqueda de la verdad en el proceso analítico. La verdad no es solo recordar y reconocer acontecimientos del pasado y del presente y dotarlos del sentido correcto, acorde con la coherencia del discurso, sino también la vivencia de una relación genuina que permita compensar las carencias evolutivas. Estas carencias no permiten en principio ser expresadas en palabras, pero, según sospechamos por la manera en que han evolucionado algunos casos concretos y por lo que se dice del tratamiento con pacientes psicosomáticos, tal vez no llegan a ser expresadas verbalmente nunca pero, de manera sorprendente, se produce el cambio y, modestamente, la curación, como resultado de una relación básicamente emocional, aunque no renunciemos al plano intelectual en el análisis de los conflictos, mediante interpretación, clarificación y confrontación. En esas situaciones, como en otras, la verdad es algo que se alcanza en grupo, participando de todos los modos enunciados a lo largo de este texto: coherencia, descubrimiento, y, ¿cómo no?, como autenticidad. Tal vez esta propuesta merezca la crítica de permitir el dominio de la conciencia ideológica, frente a la conciencia científica, pero hace tiempo que aprendimos a desconfiar de una fe ciega en la ciencia - por no hablar de la técnica - disfrazada de indagación neutral y desprejuiciada. Cierta ideología será admisible, por ejemplo, cuando favorezca la vida por encima de los conceptos, pues "gris es toda teoría y verde es el árbol de oro de la vida" (Goethe).

Me despido sin haber mínimamente logrado la sensación de bienestar propia de la tarea completada, es decir, la conclusión de haber respondido a cuestiones de tanta trascendencia como las planteadas en la ambiciosa introducción. Ni si quiera puedo estar medianamente convencido del valor intrínseco de lo dicho, mas, recordando el verso italiano con que termina la primera parte del Quijote, diré: Forse altri canterà con miglior plettro ("Quizá otro cantará con mejor plectro").

\section{REFERENCIAS}

Abello, A. y Liberman, A. (2011). Una Introducción a la Obra de D. W. Winnicott. Contribuciones al Pensamiento Relacional. Madrid: Ágora Relacional.

Aron, L. (1996). A meeting of minds: Mutuality in psychoanalysis. Hillsdale, New Jersey: Analytic Press.

Atwood, G.E. (2014). La psicoterapia como ciencia humana: Estudios de casos clínicos que exploran el abismo de la locura. Clínica e Investigación Relacional, 8 (3): 291-322. 
Ávila Espada, A. (2005). Al cambio psíquico se accede por la relación. Intersubjetivo, 2, 195-220.

Ávila Espada, A. (2013). Las aportaciones latinoamericanas: Enrique Pichon Rivière, Racker y los Baranger. En Ávila Espada (ed.) La Tradición Interpersonal. Perspectiva social y cultural en psicoanálisis. Madrid: Ágora Relacional.

Bacal, H.A. (2017). La responsividad óptima y el proceso terapéutico. Clínica e Investigación Relacional, 11 (1): 22-50. [ISSN 1988-2939] [Recuperado de www.ceir.info ] DOI: 10.21110/19882939.2017.110102

Bacal, H.A. y Carlton, L. (2017). Cómo la teoría de la especificidad cambia la práctica clínica. Clínica e Investigación Relacional, 11 (2): 232-245. [ISSN 1988-2939] [Recuperado de www.ceir.info ] DOI: 10.21110/19882939.2017.110202

Bajtín, M. (1979) Problemas de la poética de Dostoievski. Trad. de Tatiana Bubnova, Buenos Aires, Fondo de Cultura Económica: México, 2012.

Balint, M. (1979). La falta básica. Aspectos terapéuticos de la regresión. Barcelona: Paidós, 1993.

Benjamin, J. (1996). Los Lazos de Amor. Psicoanálisis, feminismo y el problema de la dominación. Buenos Aires: Paidós, 1996.

Berger, P. L. y Luckmann, T. (1986). La construcción social de la realidad. Buenos Aires: Amorrortu

Bion, W.R. (1962). Aprendiendo de la Experiencia. Buenos Aires: Paidós, 1975.

Bromberg, P.M. (2009). Truth, Human Relatedness, and the Analytic Process: An Interpersonal/Relational Perspective. International Journal of Psychoanalysis, 90, 347-361.

Bromberg, P.M. (2011). The shadow of the tsunami: and the growth of the relational mind. New York: Routledge.

Cavell, M. (1993). La mente psicoanalítica. De Freud a la Filosofía. México: Paidós, 2000.

Cavell, M. (2000). Review essay: Self-reflections. Psychoanalytic Dialogues, 10, 513-529.

Coderch, J. (2006). Pluralidad y Diálogo en Psicoanálisis. Diversidad y vinculaciones interdisciplinares. Barcelona: Herder.

Coderch, J. (2007). Conflicto, Déficit y Defecto. Clínica e Investigación Relacioonal, 1, 2, 359-371. www.psicoterapiarelacional.com/clinicaeinvestigacionrelacional.

Coderch, J. (2011). La Práctica de la Psicoterapia Relacional. Madrid: Ágora Relacional.

Descartes, R. (1641). Meditaciones Metafísicas. Con Objeciones y Respuestas. Traducción de Vidal Peña; Madrid: Alfaguara, 1977.

Espinosa, S., García-Valdecasas, S., Pinto, J.M., R. Sutil, C., Vivar, P., Aburto, M., Ávila, A. y Bastos, A. (Colectivo GRITA). (2005). Procesos de Mutualidad y Reconocimiento. Un Nuevo contexto para la reconsideración de la transferencial. Intersubjetivo, 2, 7,180-194.

Fairbairn, W.R.D. (1940). Factores esquizoides de la personalidad. En Estudio Psicoanalítico de la Personalidad. Buenos Aires: Hormé, 1978. 
Fairbairn, W.R.D. (1943). La represión y el retorno de los objetos malos. En Estudio Psicoanalítico de la Personalidad. Buenos Aires: Hormé, 1978.

Fairbairn, W.R.D. (1958). On the Nature and Aims of Psychoanalytical Treatment. En Selected Papers of W.R.D. Fairbairn. David E. Scharff \& Ellinor Fairbairn Birtles (1994) (eds.) N.J.: Jason Aronson (vol. I, Cap. 4). (On the nature and aims of psychoanalytical treatment, International Journal of Psychoanalysis, 39: 374-385).

Ferenczi, S. (1932). Confusión de lengua entre los adultos y el niño. En Obras Completas, vol IV. Madrid: Espasa-Calpe, 1982.

Ferrater Mora, J. (1986). Diccionario de Filosofía. Madrid: Alianza

Freud, S. (1894 a). Las neuropsicosis de defensa. En Obras Completas (vol. I). Madrid: Biblioteca Nueva, 1973 .

Freud, S. (1912-13). Tótem y Tabú. Algunos aspectos comunes entre la vida mental del hombre primitivo y los neuróticos. En Obras Completas (vol. II). Madrid: Biblioteca Nueva, 1973.

Freud, S. (1916-1917). Lecciones Introductorias al Psicoanálisis. En Obras Completas (vol. II). Madrid: Biblioteca Nueva, 1973. Vorlesungen zur einfürung in die Psychoanalyse (1916-17). En Studienausgabe, (vol. I), Franfurkt am Main: S. Fisher, 1997.

Freud, S. (1925 h). La Negación. En Obras Completas (vol. III). Madrid: Biblioteca Nueva, 1973. Die Verneinung. En Studienausgabe (vol. III). Frankfurt am Main : S.Fisher, 1975.

Freud, S. (1933 a). Nuevas Lecciones Introductorias al Psicoanálisis. En Obras Completas (vol.III). Madrid: Biblioteca Nueva, 1973.

Freud, S. (1937b). Construcciones en Psicoanálisis. Obras Completas (vol. III). Madrid: Biblioteca Nueva, 1973. Konstructionen in der Analyse. En Studienausgabe (vol. adicional). Frankfurt am Main : S.Fisher, 1975.

Freud, S. (1939 a). Moisés y la Religión Monoteista: Tres Ensayos. En Obras Completas (vol.III). Madrid: Biblioteca Nueva, 1973. Der Mann Moses und die monotheistische Religion. En Studienausgabe (vol. IX). Frankfurt am Main : S.Fisher, 1975.

Gadamer, H-G. (1960). Verdad y Método. Salamanca: Ediciones Sígueme, 1992 (2 vol.).

Gadamer, H-G. (1975). Subjetividad e intersubjetividad, sujeto y persona. En El Giro Hermenéutico. Madrid: Cátedra, 2007.

Gerson, S. (2004). The relational unconscious: A core element of intersubjectivity, thirdness, and clinical process. Psychoanalytic Quarterly, LXXIII, 63-98.

Grondin, J. (1991). Introducción a la Hermenéutica Filosófica. Barcelona: Herder, 2002.

Grünbaum, A. (1984). The Foundations of Psychoanalysis. A Philosophical Critique. Berkeley, LA: University of California Press.

Habermas, J. (1968). Connaisance et Intérêt. París: Gallimard, 1976.

Hegel, G.W.F. (1807/1993). Fenomenología del Espíritu. Traducción de Wenceslao Roces: Madrid. 
Heidegger, M. (1927). Sein und Zeit. Tubinga: Max Niemeyer, 1993. El Ser y el Tiempo. Madrid: Fondo de Cultura Económica, 1989.

Heidegger, M. (1943). Vom Wessen der Warheit. De lésence de la vérité. http://aphelis.net/wpcontent/uploads/2011/02/Martin-Heidegger-On-the-Essence-of-Truth.pdf. En Questions / et II. París: Gallimard, 1968.

Heidegger, M. (1987). Zollikon Seminars. Protocols-Conversations-Letters. M. Boss (ed.). R. Askay \& F. Mayr (trs.). Northwestern University Press: Evanston, IL, 2001.

Killingmo, B. (1999). Revisión de la denominada "Regla de Abstinencia". Intersubjetivo, 1,1, 6578.

Kohut, H. (1957). Clinical and Theoretical Aspects of Resistance. Journal of the American Psychoanalytical Association, 5, 548-555

Kohut, H. (1984), How Does Analysis Cure? Ed. A. Goldberg \& P. E. Stepansky. Chicago: University of Chicago Press. Traducción castellana ¿Cómo Cura el Análisis? Buenos Aires: Paidós, 1986.

Lacan, J. (1953-54). Seminario I. Los escritos técnicos de Freud. Barcelona: Paidós, 1986.

Lacan, J. (1956). Le séminaire sur « La Lettre volée ». En Écrits. París: Seuil (vol. I), 1966.

Lacan, J. (1957). L'instance de la lettre dans l'inconscient ou la raison depuis Freud. En Écrits. París: Sevil (vol. I), 1966.

Lacan, J. (1959-60). Seminario VII. La Ética del Psicoanálisis. Barcelona : Paidós, 2005.

Lacan, J. (1960a). Subversion du sujet et dialectique du désir dans l'inconscient freudien. En Écrits. París: Seuil (vol. II), 1966. Subversión del sujeto y dialéctica del deseo en el inconsciente freudiano. En Escritos, vol 1. México: Siglo XXI, 1977.

Lacan, J. (1964 a). Du "Trieb" de Freud et du désir du psychanalyste. En Écrits. París: Seuil (vol. II), 1966.

Lacan, J. (1964b). Seminario XI. Los Cuatro Conceptos Fundamentales del Psicoanálisis. Buenos Aires: Paidós, 1997.

Lacan, J. (1966). Écrits. París: Seuil (vol. I), 1970. La instancia de la letra en el inconsciente o la razón desde Freud. En Escritos, vol 1. México: Siglo XXI, 1977.

Lacan, J. (1972-73). Seminario XX. Aún. Barcelona: Paidós, 1981.

Loparic, Z. (1999). Winnicott and Heidegger. www.interleft.com.br/loparic/zeljko/pdfs/Heidand\%20winni_68.pdf

Levenson, E.A. (2012) . Psychoanalysis and the Rite of Refusal. Psychoanalytic Dialogues, 22:26.

Lyons-Ruth, K. (1999). The Two-Person Unconscious: Intersubjective Dialogue, Enactive Relational Representation, and the Emergence of New Forms of Relational Organization. Psychoanalytic Inquiry, 19, 576-617

MacIntyre, A. (1958). El Concepto de Inconsciente. Buenos Aires: Amorrortu, 2001. 
Mitchell, S.A. (1988). Relational concepts in psychoanalysis: An integration. Cambridge, Massachussets: Harvard University Conceptos relacionales en psicoanálisis. Una integración. Mexico: Siglo XXI editores.

Mitchell, S.A. (1993). Hope and Dread in Psychoanalysis. New York: Basic Books.

Mitchell, S.A. (2000). Relationality. From Attachment to Intersubjetivity. New York: The Analytic Press.

Orange, D.M. (2010). Thinking for Clinicians. Philosophical Resources for Contemporary Psychoanalysis and the Humanistic Psychotherapies. Nueva York: Routledge.

Orange, D.M. (2011). "La Actitud de los Héroes": Bernard Brandchaft y la Hermenéutica de la Confianza. Comunicación presentada en el Congreso IARPP, Madrid, Junio, 2011.

Orange, D.M., Atwood, G.E. y Stolorow, R.D. (1997). Working intersubjectivity: Contextualism in psychoanalytic practice. Hillsdale, NJ: Analytic Press.

Ortega y Gasset, J. (1914). Meditaciones del Quijote. Madrid: Alianza, 1998.

Ortega y Gasset, J. (1947). En torno a Galileo. Madrid: Alianza, 1982.

Platón. Fedón. Buenos Aires: Aguilar, 1977.

Platón. Teeteto, o de la Ciencia. Buenos Aires: Aguilar, 1977.

Pöggeler, O. (1983). El camino del pensar de Martin Heidegger. Madrid: Alianza, 1986.

Renik, O. (1995). The ideal of the anonymous analyst and the problem of self- disclosure. Psychoanalytic Quarterly, 64, 466-495.

Ricoeur, P. (1965). De l'Interpretation. París : Éditions fu Seuil.

Ricoeur, P. (1977). La cuestión de la prueba en psicoanálisis. Escritos y Conferencias, 1. En torno al Psicoanálisis. Madrid: Trotta, 2013.

Ricoeur, P. (1998). La Identidad Narrativa. En "Historia y Narratividad". Barcelona: Paidós, 1999.

Rodríguez-Sutil, C. (2007). Epistemología del psicoanálisis relacional. Clínica e Investigación Relacional, 1 (1): 9-41.

Rodríguez Sutil, C. (2014). Psicopatología Psicoanalítica Relacional. Madrid: Ágora Relacional.

Szpilka, J. (1973). Bases para una psicopatología psicoanalítica. Buenos Aires: Kargieman.

Stern, Daniel (1983)., The early development of schemas of self, other, and 'self with other'. En J.D. Lichtenberg y S. Kaplan (comps.), Reflections on Self Psychology, Hillsdale, N.J. : The Analytic Press, pp. 49-84.

Stolorow, R. \& Atwood, G. (1992). Contexts of being: The intersubjective foundations of psychological life. Hillsdale, NJ: Analytic Press.

Stolorow, R.D., Orange, D.M., y Atwood, G.E. (2001). Cartesian and post-Cartesian trends in relational psychoanalysis. Psychoanalytic Psychology, 18, 468-484. 
Velasco, R. (2005). Comprensión relacional de la transferencial en el vínculo analítico. Intersubjetivo, 7, 2, 172-179.

Winnicott, D.W. (1956). Preocupación maternal primaria. En Escritos de Pediatría y Psicoanálisis. Barcelona: Paidós, 1999.

Winnicott, D.W. (1965). True and False Self. En The Maturational Process and the Facilitating Environment. Londres: Hogart Press.

Winnicott, D.W. (1969). El uso de un objeto y la relación por medio de identificaciones. Capítulo 6 de Realidad y Juego, Buenos Aires: Gedisa, 1972.

Wittgenstein, L. (1918). Tractatus Logico-Philosophicus. Edición bilingüe alemán-español de Jacobo Muñoz e Isidoro Reguera; Madrid :Alianza, 1987.

Wittgenstein, L. (1945-49). Philosophical Investigations. Traducción inglesa de G.E.M. Anscombe; Oxford: Basil Blackwell, 1984. Revised $4^{\text {th }}$ edition by P.M.S. Hacker and Joachim Schulte. Oxford: Wiley-Blackwell, 2009: Edición bilingüe alemán-español de Alfonso García Suárez y Ulises Moulines "Investigaciones Filosóficas"; Barcelona: Crítica, 1988.

Wittgenstein, L. (1945-1948). Zettel. Traducción inglesa de G.E.M. Anscom^be; Oxford: Basil Blackwell, 1981.

Wittgenstein, L. (1949). On Certainty. Oxford: Basil Blackwell, 1974.

Woodfield, A. (1987). On the very idea of acquiring a concept. En J.Russell (ed.) Philosophical Perspectives on Developmental Psychology. Oxford: Basil Blackwell, pp. 17-30.

Original recibido con fecha: 15/02/2019 Revisado: 30/03/2019 Aceptado: 30/03/2019

NOTAS:

\footnotetext{
${ }^{1}$ Una buena introducción puede encontrarse en Ferrater Mora (1986), en su monumental diccionario, y que aquí se retoma en algunos puntos.

${ }^{2}$ Véanse, no obstante, las referencias sobre la aletheia que se contienen en la obra temprana de Ortega (1914)

3 "To tally with" es adecuarse a o corresponder con.

4 Es hat natürlich keine Schwierigkeit, ihn zum Anhänger einer gewissen Theorie zu machen und ihn so auch an einem möglichen Irrtum des Arztes teilnehmen zu lassen. Er verhält ssich dabei wie ein anderer, wie ein Schüler, aber man hat dadurch auch nur seine Intelligenz, nicht seine Krankheit beeinflusst. Die Lösung seiner Konflikte und die Überwindung seiner Widerstände glückt doch nur, wenn man ihm solche Erwartungsvorstellungen gegeben hat, die mit der Wirklichkeit in ihm übereinstimmen. Was an den Vermutungen der Arztes unzutreffend war, das fällt im Laufe der Analyse wieder heraus, muss zurückgezogen un durch Richtigeres ersetzt werden. (Edición alemana, pp. 434-435)
} expresa. Este material es para uso científico y profesional exclusivamente y puede contener información clínica sensible. Los editores no se responsabilizan de los contenidos de los autores. Dirigir las consultas sobre derechos y autorizaciones a ceir@psicoterapiarelacional.es 